\title{
SABERES BOTÁNICOS EN EL TALAR: UTILIZACIÓN DE PLANTAS SILVESTRES con fines medicinales y alimenticios en el Parque Costero del Sur (partidos de Magdalena y Punta Indio, Buenos Aires, República Argentina)
}

\author{
Naiquen Ghiani Echenique ${ }^{*}$, María Belén DoumecQ ${ }^{2}$ y María Lelia Pochettino ${ }^{2,3}$
}

\author{
${ }^{1}$ Laboratorio de Análisis Cerámico. Facultad de Ciencias Naturales y Museo. UNLP. E-mail:naiqueng@gmail.com \\ ${ }^{2}$ Laboratorio de Etnobotánica y Botánica Aplicada. Facultad de Ciencias Naturales y Museo. UNLP. \\ ${ }^{3}$ CONICET \\ *Autorpara correspondencia: naiqueng@gmail.com
}

Recebido em 07 de julho de 2016. Aceito em 13 de fevereiro de 2017. Publicado em 06 de abril de 2018.

\begin{abstract}
Resumen - La Reserva de Biosfera "Parque Costero del Sur" (PCS) se encuentra ubicada en los partidos de Magdalena y Punta Indio, en el noreste de la Provincia de Buenos Aires. Esta figura de protección se fundamenta en su riqueza en biodiversidad, donde la presencia del bosque costero, constituido por talares, se conjuga con ambientes de bañados y playa. Resulta de interés indagar la diversidad vegetal del PCS y su aprovechamiento por parte de los habitantes locales con miras a su constitución como patrimonio intangible. En este sentido, desde un enfoque etnobotánico se plantea caracterizar la utilización de recursos vegetales silvestres con fines alimenticios y medicinales en el Parque Costero del Sur. Mediante entrevistas a los pobladores locales se relevaron 54 especies vegetales utilizadas, se abordaron las prácticas y saberes relacionados, como así los modos de utilización y las condiciones en que tiene lugar su obtención y consumo. El análisis del conocimiento botánico local permite reflexionar sobre la valoración de estas especies vegetales como alimento y/o medicamento y su importancia para la población actual, así como indagar la posibilidad de una valoración diferencial de la recolección de plantas medicinales respecto de las alimenticias. Con los resultados obtenidos se propone fomentar la participación de los pobladores en actividades de capacitación sobre recursos vegetales locales, y contribuir mediante la realización de un material informativo a distribuirse entre pobladores y visitantes del PCS.
\end{abstract}

Palabras Clave: Parque Costero Del Sur; Etnobotánica; Recursos Vegetales Silvestres; Plantas Alimenticlas; Plantas MEDicinales.

Conhecimento botânico no talar: uso de plantas silvestres com fins medicinais e alimentícios no Parque Costero del Sur (regiẽo de Magdalena e Punta Indio, Buenos Aires, República Argentina)

Resumo - Reserva da Biosfera "Parque Costero del Sur" (PCS) situa-se em região de Magdalena e Punta Indio, no nordeste da província de Buenos Aires. Esta unidade de proteção baseia-se na sua riqueza em biodiversidade, onde a presença da floresta costeira, constituída pelo talar, combina com ambientes de praia e zonas úmidas. É interessante a investigação da diversidade vegetal do PCS e sua utilização pela população local, tendo em vista a sua constituição como patrimônio imaterial. Neste sentido, a partir de um enfoque etnobotânico caracterizou-se a utilização dos recursos de plantas selvagem para fins alimentícios e medicinais em PCS. Entrevistando os moradores locais, 54 espécies vegetais utilizadas foram registradas, e as práticas e conhecimentos relacionados, foram abordados bem como os modos de utilização e as condições em que tem lugar a recolha e o consumo. A análise do conhecimento botânico local para refletir sobre a valorização dessas plantas como alimento ou medicamento e sua importância para a população atual, bem como para investigar a 
possibilidade de uma avaliação diferencial da colheita de plantas medicinais e para a comida. Com os resultados obtidos pretende-se promover a participação dos residentes em ações de formação sobre os recursos locais e contribuir com a produçao de um folheto para ser distribuído para os moradores e visitantes dos PCS.

Palavras-Chave: Parque Costero Del Sur; Etnobotânica; Recursos De Plantas Selvagem; Plantas Alimentíclas; PlaNTAS MEDICINAIS.

\section{Botanical KNowledge of talar: uSE of Wild plants for medicinal and food purposes in Parque Costero del Sur} (regions of Magdalena and Punta Indio, Buenos Aires, Argentina)

Abstract - "Parque Costero del Sur" Biosphere Reserve (PCS) is located in the region of Magdalena and Punta Indio, northeast of Buenos Aires province. This protected unit is based on its richness in biodiversity, where the coastal forest, constituted by the talar, combines with wetland environments and beach. It is of interest to research the plant diversity of the PCS and its utilization by local people with regards to become an intangible heritage. Therefore, from ethnobotanical point of view, the use of wild plant resources for food and medicinal purposes in PCS was characterized. By interviewing local residents, 54 used plant species have been recorded, as well as the related knowledge and practices together with the modes of use and the conditions under which harvest and consumption take place. The analysis of local botanical knowledge allowed us to reflect the assessment of these species as food or medicine and its importance to the present population, as well as to inquire about the possibility of a different evaluation of medicinal and food plants harvest. The obtained results propose to promote the participation of residents in training activities on local plant resources. In this respect, a booklet will be produced and distributed to the residents and visitors of the PCS as well.

Keywords: Parque Costero Del Sur; Ethnobotany; Wild Plant Resources; Food Plants; Medicinal Plants.

\section{INTRODUCCIÓN}

La Reserva de Biosfera "Parque Costero del Sur" (PCS) se encuentra ubicada en los partidos de Magdalena y Punta Indio, en el noreste de la Provincia de Buenos Aires, unos $60 \mathrm{~km}$ al sur de la ciudad de La Plata (Figura 1).

Figura 1 - Ubicación del Parque Costero del Sur en los partidos de Magdalena y Punta Indio, provincia de Buenos Aires, República Argentina.

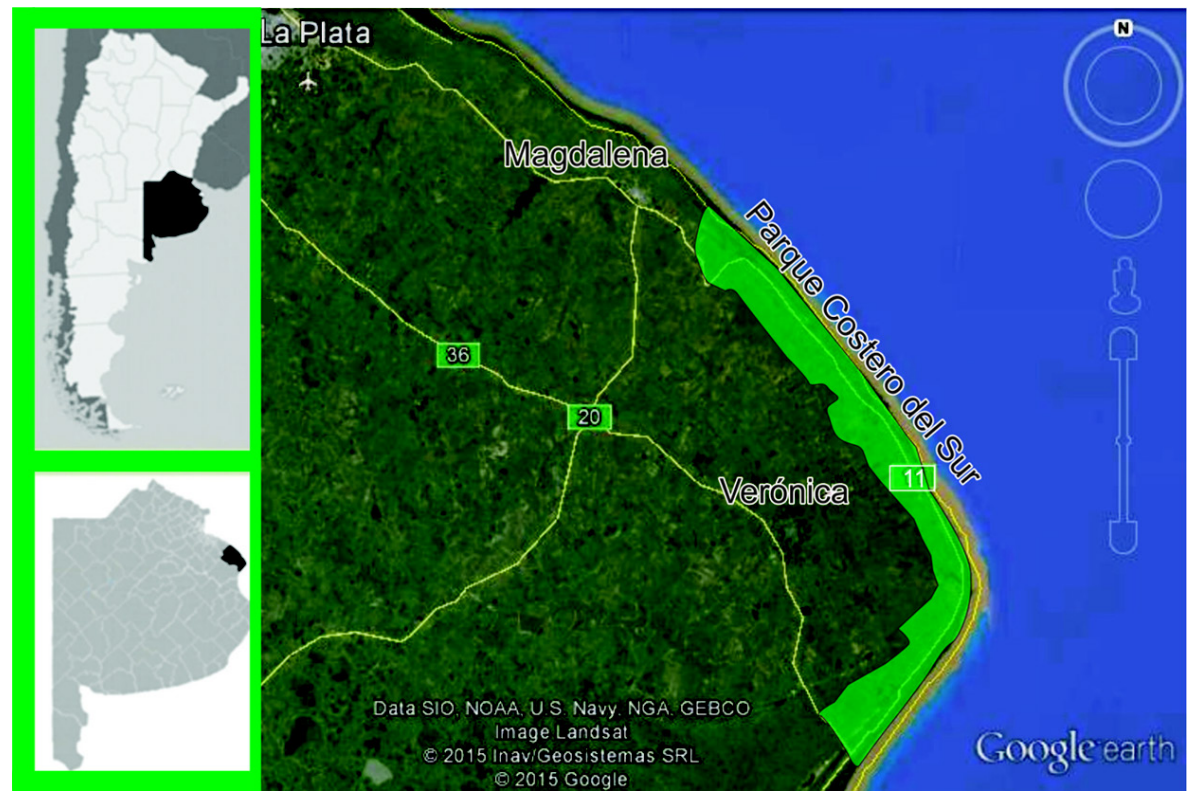


La identificación de un valioso patrimonio natural y cultural en la zona por parte de la fundación CEPA (Centro de Estudios y Proyectación del Ambiente), originó la propuesta de protección del área, entendiendo su afinidad con el programa Man and Biosphere (MaB) de la Organización de las Naciones Unidas para la Educación, la Ciencia y la Cultura (UNESCO). Dicho programa busca conciliar el desarrollo humano con la valoración del patrimonio natural-cultural a fin de propiciar la conservación de la biodiversidad y el desarrollo sustentable en la producción local. En consecuencia, el 8 de diciembre de 1984 el PCS fue declarado Reserva Mundial de Biosfera Natural y Cultural (CEPA 1989). Además, a nivel provincial el PCS ha sido declarado Refugio de Vida Silvestre en el año 1997, con las consiguientes incumbencias legales y administrativas del Ministerio de Asuntos Agrarios de la provincia de Buenos Aires. Esta figura de protección se fundamenta en su riqueza en biodiversidad, donde la presencia del bosque costero constituido por talares (bosques de Celtis ehrenbergiana (Klotzsch) Liebm.) se conjuga con ambientes de bañados y playa (Figura 2).

Figura 2 - Paisajes del Parque Costero del Sur. A-Balneario El Pericón, zona de playa; B-Ruta Provincial N¹1; a ambos lados de la misma hay vegetación ruderal, donde los pobladores recolectan algunas plantas.
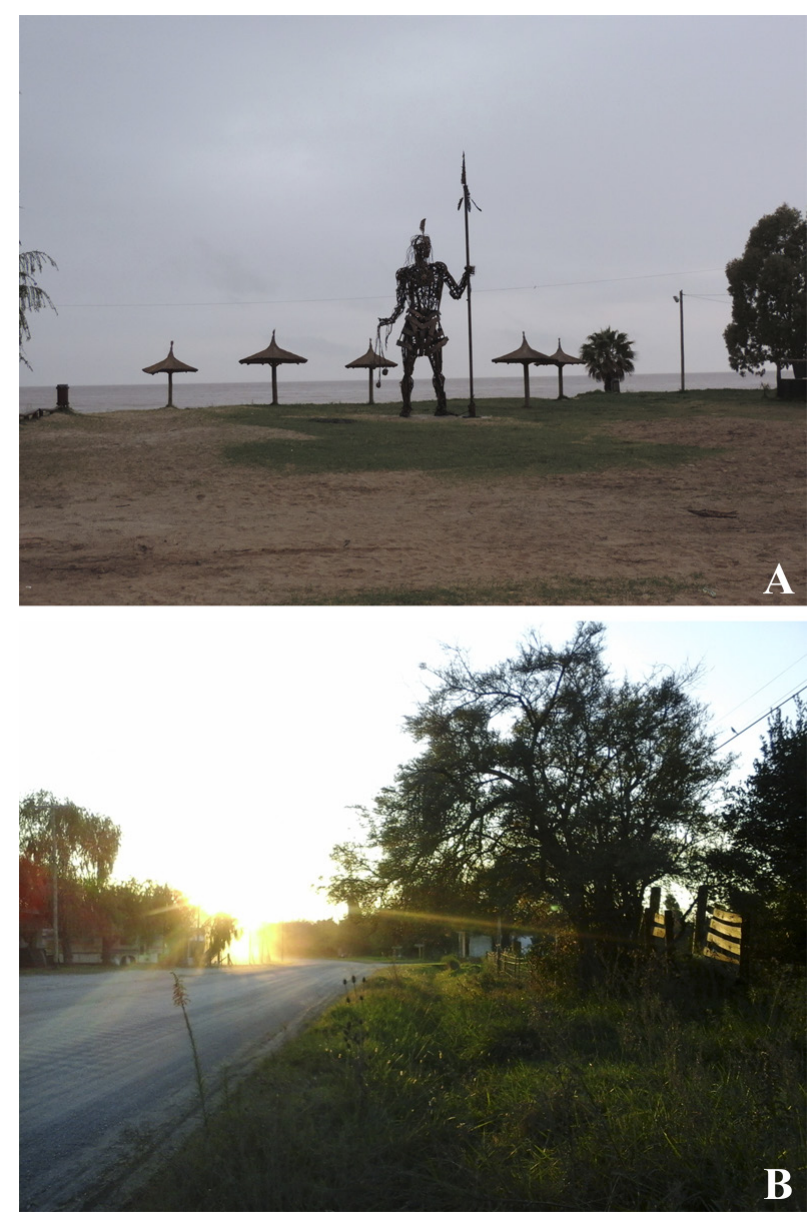

El uso no sustentable de recursos por parte de algunos pobladores e instituciones se expresa en diversas prácticas fuertemente cuestionadas por el resto de la comunidad por generar problemas ambientales. Las principales actividades económicas en los campos privados que componen el PCS son la ganadería y la extracción de conchilla del sustrato (Arturi et al. 2009). Estas actividades afectan la estructura y superficie de los bosques, la composición florística y el relieve; por ejemplo, la tala indiscriminada ha llevado a una reducción de los talares, elemento notoriamente alterado en la actualidad (Torres-Robles y Arturi 2009). El tala y otros árboles 
del bosque costero se utilizan para leña e incluso tiene lugar su comercialización. Es notoria la falta de control de la tala indiscriminada así como de la extracción de conchilla y la caza y pesca furtiva. Por otro lado, los emprendimientos de producción intensiva de ganado provocan contaminación de aguas subterráneas y olores desagradables. También se identifica la existencia de basurales a cielo abierto. Resulta conflictiva además la llegada de nuevos habitantes provenientes del gran Buenos Aires, que tienen hábitos y costumbres diferentes a las locales (Rossi y Molinari 2012a, 2012b).

La situación descripta plantea un doble interés entre los pobladores. Por un lado, demuestran preocupación por temas ambientales, muchas veces motivada por falta de controles estatales en cuanto a la depredación ambiental identificada como una problemática local (Stratta-Fernández y De los Ríos-Carmenado 2010). Por otra parte, localmente se manifiesta el interés del desarrollo de la zona como polo turístico.

En este sentido, se plantea la necesidad de un desarrollo del sector de servicios frente a la demanda turística, pero compatible con el carácter de área protegida de la zona. Con el aporte de profesionales de la UNLP se ha planificado localmente una estrategia de desarrollo a fines de fomentar el turismo y hacer sostenible la protección del patrimonio local. Por otra parte y mediante la ejecución de proyectos diseñados por la propia comunidad, se está trabajando en la reproducción de plantas autóctonas para reforestación, en la realización de cartelería apropiada, en la construcción de senderos y de un centro de interpretación ambiental en el PCS. Este proceso dio origen a la Asociación Civil “Amigos del Parque Costero del Sur" (Stratta-Fernández y De los RíosCarmenado 2010; Rossi y Molinari 2012a), de importancia local. Cabe destacar que en los últimos tiempos se han realizado talleres y caminatas de plantas silvestres comestibles por iniciativa de pobladores locales.

Con el fin de acompañar este proceso, un equipo de investigación interdisciplinario de la Facultad de Ciencias Naturales y Museo de la Universidad Nacional de La Plata ha comenzado a desarrollar estudios enmarcados en los lineamientos de la Convención para la Salvaguardia del Patrimonio Cultural Inmaterial de UNESCO, del año 2003, y pretende recorrer los primeros pasos en la patrimonialización de la diversidad biocultural del área de estudio al aportar a la conservación de los recursos y de los conocimientos locales vinculados (UNESCO 2003). En un contexto pluricultural y en proceso de cambio como el descripto se pierde de vista, en general, el valor patrimonial de los saberes. Comúnmente se considera que la patrimonialización implica la fosilización (en el sentido de inmutabilidad) o el congelamiento de las prácticas, conocimientos, creencias y recursos biológicos asociados, en un momento dado, como freno a su irremisible pérdida. Sin embargo, si se asocia el valor del patrimonio a la consolidación de la identidad cultural del grupo, el patrimonio adquiere valor en función de su capacidad como elemento de identificación y de apropiación del entorno inmediato por parte de la comunidad. Las teorías y métodos vinculados tanto a la determinación de los bienes culturales como a su tratamiento, conducen a operaciones creativas de rescate y conservación de los mismos. Para ello es necesario atender a la lectura que de este patrimonio hace la gente, es decir, la mirada de los individuos que reconocen el ambiente de su grupo sociocultural (Guglielmino 2007).

Desde esta perspectiva teórica resultó de interés indagar la diversidad vegetal del PCS y su aprovechamiento por parte de los habitantes locales. De esta forma mediante un enfoque etnobotánico se plantea caracterizar la utilización de recursos vegetales espontáneos (independientemente de su origen nativo o exótico) con fines alimenticios y medicinales en el Parque Costero del Sur. En este sentido, se analizaron estudios locales referidos a malezas comestibles con productores hortícolas (Pochettino 2005) y a plantas medicinales de localidades de la costa rioplatense (Hernández et al. 2010, 2011) cuyos resultados condujeron a suponer una mayor preponderancia 
del uso de plantas medicinales en relación al de alimenticias, supuesto testeado a través de este trabajo.

\title{
MATERIALES Y MÉTODOS
}

\author{
Área de estudio
}

El área de estudio corresponde a la Reserva de Biosfera "Parque Costero del Sur" (PCS), la cual se inicia después del predio del Regimiento Octavo de Infantería en el partido de Magdalena y finaliza en la intersección de las Rutas Provinciales No 11 y No 36, partido de Punta Indio, en la provincia de Buenos Aires (Figura 1). Abarca una franja de $5 \mathrm{~km}$ de ancho por $70 \mathrm{~km}$ de largo sobre el margen sur del Río de La Plata, y presenta una superficie de 35.000 hectáreas.

Desde el punto de vista fitogeográfico, el área de estudio está situada en el borde oriental de la Provincia Pampeana propuesta por Cabrera (1971), la cual se caracteriza por la preponderancia de pastizales o estepas graminosas cuya comunidad clímax es el flechillar, que se extiende sobre campos altos con suelos húmicos y arcillo-arenosos ligeramente ácidos (Abba et al. 2009). En el sector costero existe una formación vegetal particular, conocida como talar o bosque de tala, la cual posee elementos florísticos afines a la Provincia Fitogeográfica del Espinal (Cabrera 1971, Burkart et al. 1999, entre otros). La misma se desarrolla a partir del suelo formado sobre los cordones de conchilla existentes en este sector, con disposición paralela y subparalela a la costa, cuya conformación estuvo vinculada a los cambios en el nivel del mar ocurridos durante el Holoceno (Cavallotto 2002, 2009). Dichos cordones determinan la presencia de ondulaciones características del terreno en este paisaje costero. En cuanto a su vegetación, el talar está conformado por ocho especies arbóreas definitorias que se encuentran en asociación con pastizales, trepadoras y rastreras. Estas son Celtis ebrenbergiana, Scutia buxifolia Reissek, Jodina rhombifolia (Hook. \& Arn.) Reissek, Schinus longifolius (Lindl.) Speg., Sambucus australis Cham. \& Schltdl., Sapium haematospermum Müll. Arg., Phytolacca dioica L. y Colletia spinosissima J.F. Gmelin. El talar alterna con pastizales en zonas altas y con vegetación hidrófila en zonas bajas. Por otro lado, en el PCS se observa la presencia de numerosas especies vegetales exóticas, muchas de las cuales se han naturalizado, como Laurus nobilis L., Matricaria recutitta L., Taraxacum officinale G.H. Webber y Morus alba L. Otras especies resultan invasoras, por ejemplo Lonicera japonica L., Gleditsia triacanthos Thos L. y Ligustrum lucidum Ait. F. (Delucchi y Torres-Robles 2009). La variedad de ecosistemas presentes en el PCS en vinculación con elementos antrópicos conforman un paisaje que da cuenta de una prolongada historia de ocupación humana desde momentos prehistóricos. De todos modos, a pesar de no estar densamente poblada, la zona ha sufrido continuas modificaciones de forma tal que los comúnmente denominados "ambientes naturales" en realidad constituyen el resultado de la interacción entre el hombre y su entorno (Paleo y Pérez Meroni 2010).

A fines de caracterizar a la población humana que vive dentro del PCS debe considerarse la distribución poblacional de los partidos involucrados de Magdalena y Punta Indio. En cada uno de estos partidos más del $50 \%$ de los habitantes se concentran en la ciudad cabecera, mientras que el resto de la población se encuentra dispersa (Baxendale 2009). Las principales actividades económicas son la ganadería y la extracción de material calcáreo del subsuelo. El mayor centro urbano dentro del parque lo constituye la localidad de Punta del Indio, ubicada sobre la Ruta Provincial N¹1 y que cuenta actualmente con una cantidad aproximada de 700 pobladores censados, aunque es frecuente observar que ciertas personas no residan de forma permanente. Otra actividad 
tradicional de la localidad es el turismo, que tiene lugar en relación al valor paisajístico de la costa y su tranquilidad (Baxendale 2009). Esta particularidad, en el marco de un partido con población mayoritariamente de origen rural y dedicada a la actividad agropecuaria, es considerada como una oportunidad para superar la situación local de despoblación de jóvenes en el campo debido a la búsqueda laboral (Stratta-Fernández y De los Ríos-Carmenado 2010; Rossi y Molinari 2012a, 2012b)

\section{Metodologia}

Es en la localidad de Punta del Indio donde se han realizado en su mayoría las entrevistas del presente trabajo, debido a la concentración y heterogeneidad poblacional que presenta dentro del PCS. Se han realizado algunas entrevistas en el paraje Punta Piedras, que cuenta con escasas viviendas y una escuela. En el restante territorio del PCS, de carácter rural, la distribución dispersa de la población dificulta un abordaje sistemático. Muchas veces los campos no cuentan con pobladores estables; los dueños viven en ciudades como Verónica, La Plata o Buenos Aires, y en caso de haber peones residentes no es fácil establecer con ellos los contactos necesarios para la realización de entrevistas al no contar con autorización expresa de los dueños de los campos.

El trabajo de campo se realizó entre 2014 y 2015. Se realizaron caminatas a lo largo de las poblaciones y se solicitó autorización para realizar entrevistas en los domicilios ocupados. Se realizaron entrevistas en torno al uso de recursos vegetales silvestres con fines alimenticios y medicinales, el origen del conocimiento y las estrategias de obtención. Se llevaron a cabo en 16 unidades domésticas, que representan aproximadamente el 8\% del territorio abordado. Para ello se utilizó la técnica bola de nieve. Se entrevistó a personas de ambos sexos entre 20 y 75 años, y algunas de las entrevistas fueron respondidas por más de una persona, siendo en su mayoría individuales. Se realizó en cada caso una segunda entrevista a fin de corroborar los datos registrados. Como se mencionó en la introducción, el carácter silvestre refiere más bien a aquellas plantas espontáneas, es decir que son vistas por los pobladores como propias de la flora del PCS, independientemente de su origen nativo o exótico. Del total de entrevistas, 10 nos brindaron información mientras que en 6 casos los entrevistados declararon no saber acerca del tema en cuestión. Sin embargo, se incluyeron dentro de los resultados debido a que la respuesta negativa también aporta datos significativos para el estudio.

Se recolectó una muestra de cada planta mencionada por los entrevistados en su compañía en distintos espacios transitados por ellos durante sus actividades cotidianas. Con este material se confeccionaron ejemplares de herbario depositados en el Laboratorio de Etnobotánica y Botánica Aplicada de la Facultad de Ciencias Naturales y Museo de la Universidad Nacional de La Plata. Mediante el uso de material bibliográfico (Rapoport et al. 2009, Hurrell et al. 2008, Hurrell et al. 2010, entre otros), se llevó a cabo la identificación botánica de estos ejemplares, siguiendo la nomenclatura vigente en IBODA (2015). Así también, se evaluó la distribución de cada especie, considerando su carácter de espontánea (nativa o exótica naturalizada) o bien cultivada y se comparó el conocimiento local de primera mano con los usos ya conocidos a nivel regional.

\section{RESUltados Y DISCUSIÓN}

De las entrevistas realizadas, se desprende que un $62.5 \%$ de los pobladores entrevistados conoce o emplea plantas silvestres útiles a fines alimenticios y/o medicinales en el PCS. Todas las plantas alimenticias mencionadas 
son utilizadas en mayor o menor medida, mientras que 7 plantas medicinales mencionadas no son utilizadas, algunas porque el entrevistado o personas relacionadas no sufren la dolencia y otras por fragmentación del conocimiento (no se reconoce la planta, cómo usarla, o que parte usar). Los pobladores manifiestan espontáneamente haber adquirido su conocimiento por transmisión de generación en generación, lectura de libros especializados en el tema, charlas y caminatas organizadas por miembros de la comunidad. Los vegetales utilizados son recolectados principalmente del patio de sus casas y alrededores. La forma de recolección es esporádica y casual, ya que los entrevistados en general mencionaron que esta práctica no era cotidiana ni frecuente, sino que surgía a partir de la visualización del recurso. Estos resultados coinciden con el rol asignado a la recolección, principalmente de plantas alimenticias, en otras zonas urbanas o periurbanas, donde es considerada una actividad altamente marginal, incluso menospreciada (Pochettino 2005). De acuerdo con Rapoport et al. (1998) esto se debería a que el potencial utilitario de las plantas es desconocido o bien se jerarquiza la comodidad de la adquisición de productos mediante la compra. Al respecto, uno de los entrevistados, almacenero, menciona que "... antes se usaban plantas, cuando era chico y vivíamos en el campo, pero ahora no me hace falta. En el negocio tengo de todo, ¿̇ara qué voy a juntar?" (Pedro).

Fueron mencionadas en total 30 especies medicinales y 33 especies alimenticias. Por persona fueron citadas entre 0 y 22 especies alimenticias y entre 0 y 11 especies medicinales (Figura 3).

Figura 3 - Frecuencia de menciones de A) plantas alimenticias y B) plantas medicinales citadas en las entrevistas.

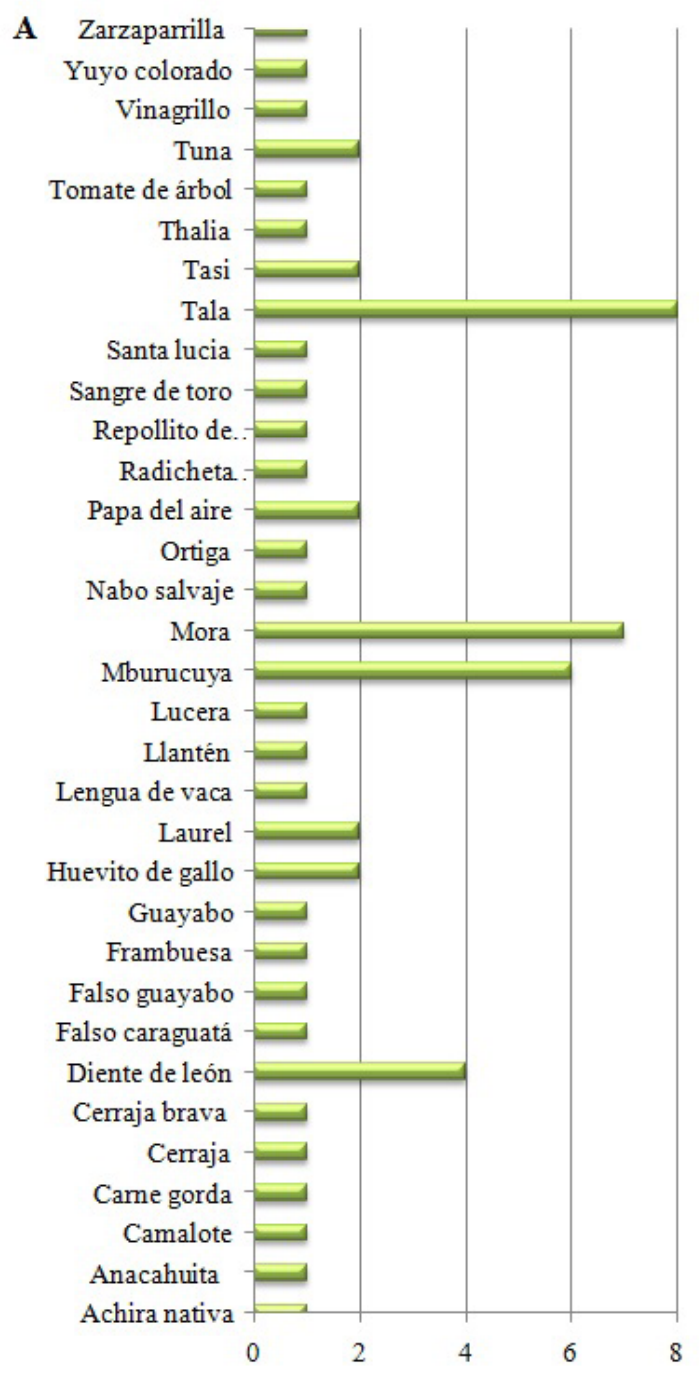

B

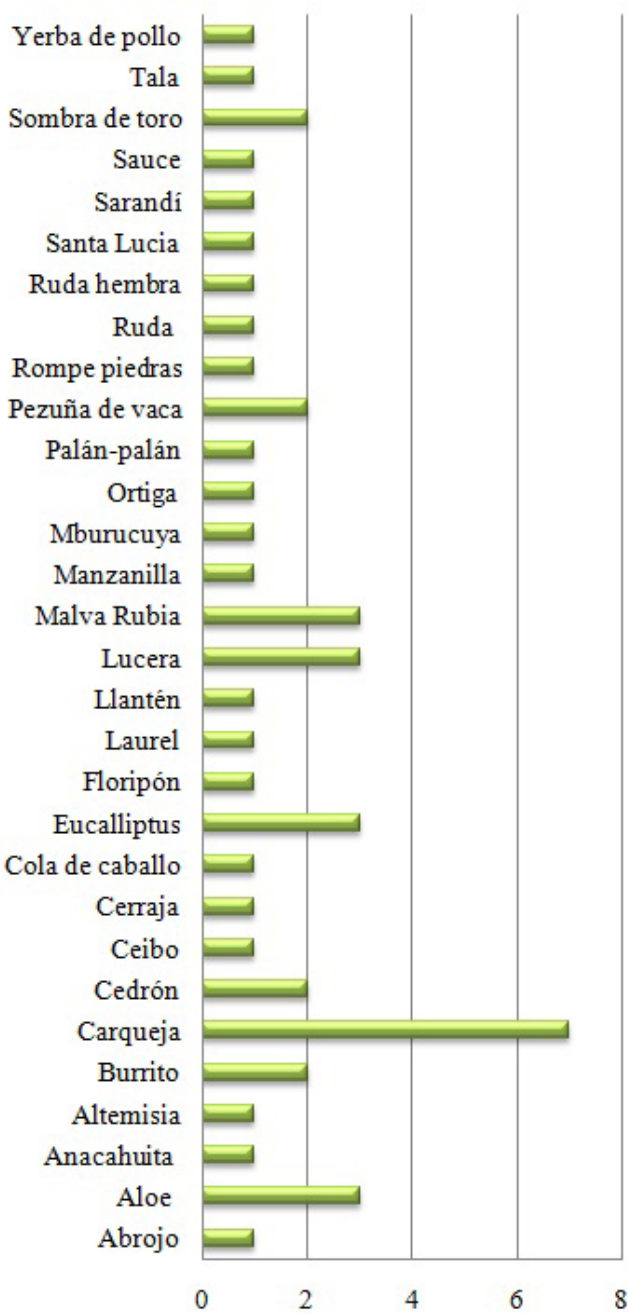


En las Tablas 1 y 2 se presentan las especies mencionadas, su carácter nativo o naturalizado, la caracterización de su uso y el vínculo con la información bibliográfica. En las Figuras 4 y 5 pueden verse algunos ejemplos. Cabe aclarar que 9 especies fueron citadas en ambos casos, es decir que dentro del PCS se conoce su valor tanto alimenticio como medicinal (Figura 6).

Tabla 1 - Plantas utilizadas con fines alimenticios en el Parque Costero del Sur. Se indica nombre vulgar, nombre científico y familia, carácter espontáneo o cultivado, parte utilizada y usos en el Parque Costero del Sur y usos registrados en la bibliografía. Los casilleros en gris corresponden a los aportes de un único entrevistado que posee amplios conocimientos vinculados a la producción de plantas y paisajismo.

\begin{tabular}{ccccc}
$\begin{array}{c}\text { Nombre } \\
\text { vulgar }\end{array}$ & $\begin{array}{c}\text { Nombre } \\
\text { científico y } \\
\text { familia }\end{array}$ & $\begin{array}{c}\text { Espontánea/ } \\
\text { cultivada }\end{array}$ & $\begin{array}{c}\text { Parte } \\
\text { utilizada y } \\
\text { usos en el } \\
\text { PCS }\end{array}$ & Usos registrados en la bibliografía \\
& & \multicolumn{3}{c}{}
\end{tabular}

$\begin{array}{llll}\text { Achira nativa } & \begin{array}{l}\text { Canna indica L., } \\ \text { Cannaceae }\end{array} & \begin{array}{l}\text { Espontánea } \\ \text { (Rapoport et } \\ \text { al. 2009). }\end{array} & \begin{array}{l}\text { Con los } \\ \text { rizomas } \\ \text { se hace } \\ \text { harina y } \\ \text { también se } \\ \text { consumen } \\ \text { los brotes } \\ \text { tiernos. }\end{array}\end{array}$

\begin{tabular}{|c|c|c|c|c|}
\hline Anacahuita & $\begin{array}{l}\text { Blepharocalyx } \\
\text { salicifolius (Kunth) } \\
\text { O. Berg, Mirtaceae }\end{array}$ & $\begin{array}{l}\text { Espontánea } \\
\text { (Lahitte y } \\
\text { Hurrell 1998). }\end{array}$ & $\begin{array}{l}\text { El fruto, } \\
\text { mentolado, } \\
\text { se come } \\
\text { crudo. }\end{array}$ & $\begin{array}{l}\text { El fruto constituye una fuente de } \\
\text { alimento para animales. En exceso } \\
\text { podría ser tóxico (Alvarado et al. } \\
\text { 2004). }\end{array}$ \\
\hline Camalote & $\begin{array}{l}\text { Eichhornia crassipes } \\
\text { (Mart.) Solms o E. } \\
\text { azurea (Sw.) Kunth, } \\
\text { Pontederiaceae }\end{array}$ & $\begin{array}{l}\text { Espontánea } \\
\text { (Rapoport et } \\
\text { al. 2009). }\end{array}$ & $\begin{array}{l}\text { La parte } \\
\text { aérea se } \\
\text { cocina } \\
\text { hervida y } \\
\text { se hacen } \\
\text { buñuelos. }\end{array}$ & $\begin{array}{l}\text { Hojas tiernas, pecíolos y pimpollos } \\
\text { se cocinan al vapor (Rapoport et al. } \\
\text { 2009). }\end{array}$ \\
\hline Carne gorda & $\begin{array}{l}\text { Talinum paniculatum } \\
\text { (Jacq.) Gaertn., } \\
\text { Talinaceae }\end{array}$ & $\begin{array}{l}\text { Espontánea } \\
\text { (Rapoport et } \\
\text { al. 2009). }\end{array}$ & $\begin{array}{l}\text { Hojas } \\
\text { crudas, en } \\
\text { ensaladas. }\end{array}$ & $\begin{array}{l}\text { Hojas y tallos tiernos se usan como } \\
\text { verduras en pasteles, pizzas, etc. } \\
\text { (Rapoport et al. 2009). }\end{array}$ \\
\hline Cerraja brava & $\begin{array}{l}\text { Sonchus asper (L.) } \\
\text { Hill, Asteraceae }\end{array}$ & $\begin{array}{l}\text { Espontánea } \\
\text { (Rapoport et } \\
\text { al. 2009). }\end{array}$ & $\begin{array}{l}\text { Con las } \\
\text { hojas } \\
\text { hervidas } \\
\text { se hacen } \\
\text { buñuelos y } \\
\text { una bebida } \\
\text { refrescante. }\end{array}$ & $\begin{array}{l}\text { Hojas y brotes tiernos se comen } \\
\text { crudos, en ensaladas mixtas o cocidas } \\
\text { como espinaca (Rapoport et al. 2009). }\end{array}$ \\
\hline
\end{tabular}




\begin{tabular}{|c|c|c|c|c|}
\hline Cerraja & $\begin{array}{l}\text { Sonchus oleraceus L, } \\
\text { Asteraceae. }\end{array}$ & $\begin{array}{l}\text { Espontánea } \\
\text { (Rapoport et } \\
\text { al. 2009). }\end{array}$ & $\begin{array}{l}\text { Con las } \\
\text { hojas } \\
\text { hervidas } \\
\text { se hacen } \\
\text { buñuelos y } \\
\text { una bebida } \\
\text { refrescante. }\end{array}$ & $\begin{array}{l}\text { Toda la planta es comestible, en } \\
\text { ensalada o cocida como espinaca } \\
\text { (Rapoport et al. 2009). }\end{array}$ \\
\hline $\begin{array}{l}\text { Diente de } \\
\text { león }\end{array}$ & $\begin{array}{l}\text { Taraxacum officinale } \\
\text { Weber, Asteraceae }\end{array}$ & $\begin{array}{l}\text { Espontánea } \\
\text { (Rapoport et } \\
\text { al. 2009). }\end{array}$ & $\begin{array}{l}\text { Hojas } \\
\text { crudas, en } \\
\text { ensaladas. }\end{array}$ & $\begin{array}{l}\text { La planta entera es comestible. Las } \\
\text { raíces crudas, picadas en ensaladas } \\
\text { o fritas se emplean para acompañar } \\
\text { papas. Se usan además para hacer } \\
\text { café. Las hojas en ensaladas o } \\
\text { hervidas para hacer albóndigas, sopas, } \\
\text { guisos, etc. Los botones florales } \\
\text { inmaduros se comen crudos, cocidos } \\
\text { o fritos. Las flores maduras se hacen } \\
\text { fritas, y también se usan para preparar } \\
\text { vino (Rapoport et al. 2009). }\end{array}$ \\
\hline $\begin{array}{l}\text { Falso } \\
\text { caraguatá }\end{array}$ & $\begin{array}{l}\text { Eryngium } \\
\text { paniculatum Cav. et } \\
\text { Domb., Apiaceae }\end{array}$ & $\begin{array}{l}\text { Espontánea } \\
\text { (Rapoport et } \\
\text { al. 2009). }\end{array}$ & $\begin{array}{l}\text { Cogollo } \\
\text { con gusto a } \\
\text { zanahoria, } \\
\text { se come } \\
\text { crudo. }\end{array}$ & $\begin{array}{l}\text { Rizomas carnosos que se consumen } \\
\text { crudos o cocidos. También al } \\
\text { rescoldo o pueden fermentarse en } \\
\text { leche. Las bases tiernas de las hojas, } \\
\text { con unas gotas de salmuera, se asan y } \\
\text { se comen como alcauciles (Rapoport } \\
\text { et al. 2009). }\end{array}$ \\
\hline $\begin{array}{l}\text { Falso } \\
\text { guayabo }\end{array}$ & $\begin{array}{l}\text { Acca sellowiana } \\
\text { (O. Berg) Burret, } \\
\text { Mirtaceae }\end{array}$ & $\begin{array}{l}\text { Cultivada } \\
\text { (Hurrell et al. } \\
\text { 2010). }\end{array}$ & $\begin{array}{l}\text { Frutos, en } \\
\text { dulce. }\end{array}$ & $\begin{array}{l}\text { Frutos se comen crudos, en } \\
\text { mermelada, jalea, jarabe, compota, } \\
\text { helado, yogur, jugo y licores. Los } \\
\text { pétalos, carnosos y dulces, son } \\
\text { comestibles (Hurrell et al. 2010). }\end{array}$ \\
\hline Frambuesa & $\begin{array}{l}\text { Rubus ulmifolius } \\
\text { Schott, Rosaceae }\end{array}$ & $\begin{array}{l}\text { Espontánea } \\
\text { (Hurrell et al. } \\
\text { 2010). }\end{array}$ & $\begin{array}{l}\text { Frutos } \\
\text { crudos o en } \\
\text { dulce. }\end{array}$ & $\begin{array}{l}\text { Frutos, frescos, cocidos, en } \\
\text { mermeladas, pasteles, compotas, } \\
\text { vinos, jugos, licores. Brotes tiernos se } \\
\text { usan como verdura y las hojas como } \\
\text { sustituto del té (Hurrell et al. 2010). }\end{array}$ \\
\hline Guayabo & $\begin{array}{l}\text { Psidium guajava L., } \\
\text { Mirtaceae }\end{array}$ & $\begin{array}{l}\text { Cultivada } \\
\text { (Hurrell et al. } \\
\text { 2010). }\end{array}$ & $\begin{array}{l}\text { Frutos } \\
\text { crudos o en } \\
\text { dulce. }\end{array}$ & $\begin{array}{l}\text { Los frutos crudos, desecados, } \\
\text { glaseados, en jaleas, dulces, pasteles, } \\
\text { helados y bebidas. Su cáscara se } \\
\text { utiliza en postres. De las semillas se } \\
\text { obtiene aceite comestible (Hurrell et } \\
\text { al. 2010). }\end{array}$ \\
\hline
\end{tabular}




\begin{tabular}{|c|c|c|c|c|}
\hline Laurel & $\begin{array}{l}\text { Laurus nobilis L., } \\
\text { Lauraceae }\end{array}$ & $\begin{array}{l}\text { Espontánea y a } \\
\text { veces cultivada } \\
\text { (Hurrell et al. } \\
\text { 2008). }\end{array}$ & $\begin{array}{l}\text { Hojas, } \\
\text { como } \\
\text { condimento }\end{array}$ & $\begin{array}{l}\text { Las hojas secas o frescas, son } \\
\text { conndimenticias. Se utilizan para } \\
\text { sopas, guisos, salsas, etc. Los frutos } \\
\text { también sirven como condimento, } \\
\text { aunque se utilizan poco; de ellos se } \\
\text { obtiene un aceite utilizado en licorería } \\
\text { (Hurrell et al. 2008). }\end{array}$ \\
\hline
\end{tabular}

\begin{tabular}{|c|c|c|c|}
\hline $\begin{array}{l}\text { Lengua de } \\
\text { vaca }\end{array}$ & $\begin{array}{l}\text { Rumex obtusifolius } \\
\text { L., Polygonaceae }\end{array}$ & $\begin{array}{l}\text { Espontánea } \\
\text { (Rapoport et } \\
\text { al. 2009). }\end{array}$ & $\begin{array}{l}\text { Hojas } \\
\text { crudas en } \\
\text { ensaladas. }\end{array}$ \\
\hline Llantén & $\begin{array}{l}\text { Plantago lanceolata } \\
\text { L. o P. major, } \\
\text { Plantagináceae }\end{array}$ & $\begin{array}{l}\text { Espontánea } \\
\text { (Rapoport et } \\
\text { al. 2009). }\end{array}$ & $\begin{array}{l}\text { Hojas } \\
\text { crudas en } \\
\text { ensaladas, } \\
\text { o cocidas } \\
\text { para hacer } \\
\text { buñuelos. }\end{array}$ \\
\hline Lucera & $\begin{array}{l}\text { Pluchea sagittalis } \\
\text { (Lam.) Cabrera, } \\
\text { Asteraceae }\end{array}$ & $\begin{array}{l}\text { Espontánea } \\
\text { (Hurrell et al. } \\
\text { 2008). }\end{array}$ & $\begin{array}{l}\text { Parte aérea } \\
\text { de la planta } \\
\text { se emplea } \\
\text { en la } \\
\text { elaboración } \\
\text { de licor. }\end{array}$ \\
\hline Mburucuyá & $\begin{array}{l}\text { Passiflora coerulea L., } \\
\text { Passifloraceae }\end{array}$ & $\begin{array}{l}\text { Espontánea } \\
\text { (Hurrell et al. } \\
\text { 2010). }\end{array}$ & $\begin{array}{l}\text { Frutos, } \\
\text { se comen } \\
\text { crudos. }\end{array}$ \\
\hline
\end{tabular}

Hojas tiernas se comen en ensaladas o cocidas en sopas, guisos, albóndigas, tortillas, etc. (Rapoport et al. 2009).

Las hojas se comen crudas en ensaladas o cocidas como espinacas. Con las semillas se hace harina. (Rapoport et al. 2009).

Hojas, tallos tiernos y capítulos como saborizante de aperitivos amargos (Hurrell et al. 2008).

se emple

elaboración licor.

Frutos comestibles crudos, en mermeladas o bebidas. También a modo de verdura, fritos o hervidos en guisos, pucheros, locros. La planta entera se usa para hacer té o mate (Hurrell et al. 2010).

\begin{tabular}{|c|c|c|c|c|}
\hline Mora & $\begin{array}{l}\text { Morus alba L., } \\
\text { Moraceae }\end{array}$ & $\begin{array}{l}\text { Espontánea } \\
\text { y cultivada } \\
\text { (Hurrell et al. } \\
\text { 2010). }\end{array}$ & $\begin{array}{l}\text { Frutos } \\
\text { crudos o en } \\
\text { dulce. }\end{array}$ & $\begin{array}{l}\text { Frutos crudos, en jaleas, mermeladas, } \\
\text { pasteles, vinos y otras bebidas. Las } \\
\text { hojas sirven para hacer té (Hurrell et } \\
\text { al. 2010). }\end{array}$ \\
\hline Nabo salvaje & $\begin{array}{l}\text { Brassica rapa L., } \\
\text { Brassicaceae }\end{array}$ & $\begin{array}{l}\text { Espontánea } \\
\text { (Rapoport et } \\
\text { al. 2009). }\end{array}$ & Tallitos & $\begin{array}{l}\text { Hojas y tallos tiernos en ensaladas } \\
\text { crudos o cocidos. Las flores se } \\
\text { preparan como brócoli y las } \\
\text { semillas molidas son condimenticias } \\
\text { (Rapaport et al. 2009) }\end{array}$ \\
\hline Ortiga & $\begin{array}{l}\text { Urtica urens L., } \\
\text { Urticaceae }\end{array}$ & $\begin{array}{l}\text { Espontánea } \\
\text { (Rapoport et } \\
\text { al. 2009). }\end{array}$ & $\begin{array}{l}\text { Hojas } \\
\text { cocidas, } \\
\text { se hacen } \\
\text { buñuelos. }\end{array}$ & $\begin{array}{l}\text { Las hojas se usan como espinaca, } \\
\text { especialmente en sopas (Rapoport et } \\
\text { al. 2009) }\end{array}$ \\
\hline
\end{tabular}




\begin{tabular}{|c|c|c|c|c|}
\hline Papa del aire & $\begin{array}{l}\text { Sechium edule (Jaq.) } \\
\text { Sw., Cucurbitaceae }\end{array}$ & $\begin{array}{l}\text { Cultivada, a } \\
\text { veces crece } \\
\text { adventicia } \\
\text { (Hurrell et al. } \\
\text { 2009). }\end{array}$ & $\begin{array}{l}\text { Fruto } \\
\text { cocido. }\end{array}$ & $\begin{array}{l}\text { Los frutos se comen crudos, o } \\
\text { cocidos en guisos, sopas, frituras, } \\
\text { tartas, budines, a modo de papas. } \\
\text { Las semillas salteadas tienen sabor } \\
\text { a nuez. Brotes tiernos y hojas se } \\
\text { comen como verdura. Las raíces se } \\
\text { comen hervidas, horneadas, fritas o } \\
\text { azucaradas (Hurrell et al. 2009). }\end{array}$ \\
\hline $\begin{array}{l}\text { Pisingallo o } \\
\text { huevito de } \\
\text { gallo }\end{array}$ & $\begin{array}{l}\text { Salpichroa } \\
\text { origanifolia (Lam.) } \\
\text { Baill, Solanaceae }\end{array}$ & $\begin{array}{l}\text { Espontánea } \\
\text { (Hurrell et al. } \\
\text { 2010). }\end{array}$ & $\begin{array}{l}\text { Frutos se } \\
\text { comen } \\
\text { crudos. }\end{array}$ & $\begin{array}{l}\text { Frutos frescos, como dulce o en } \\
\text { almíbar (Hurrell et al. 2010). }\end{array}$ \\
\hline $\begin{array}{l}\text { Radicheta } \\
\text { salvaje }\end{array}$ & $\begin{array}{l}\text { Cichorium intybus L., } \\
\text { Asteraceae }\end{array}$ & $\begin{array}{l}\text { Espontánea } \\
\text { (Rapoport et } \\
\text { al. 2009). }\end{array}$ & $\begin{array}{l}\text { Hojas } \\
\text { crudas en } \\
\text { ensaladas. }\end{array}$ & $\begin{array}{l}\text { Hojas crudas en ensaladas. Las raíces } \\
\text { secas, tostadas y molidas se usan para } \\
\text { preparar un reemplazante del café } \\
\text { y cuando tiernas pueden hervirse o } \\
\text { freírse (Rapoport et al. 2009). }\end{array}$ \\
\hline
\end{tabular}

Repollito de agua

Sangre de toro

Santa lucia

Tala

Tasi

Aranjia sericifera Brot., Apocynaceae
Espontánea (Rapoport et al. 2009).
Rivina bumilis L., Phytolacaceae
Espontánea

(IBODA 2015).

Commelina ercta L., Espontánea Commelinaceae

Celtis ebrenbergiana (Klotzsch) Liebm., Celtidaceae
(Rapoport et al. 2009).

Espontánea (Hurrell et al. 2010, TorresRobles y Arturi 2009).

Espontánea Frutos (Hurrell et al. crudos. 2010).
La parte aérea de la planta se quema para hacer un polvo que sirve de sal.

Tallos tiernos, terminales.

Frutos crudos, en dulce o licor.

Frutos crudos.

Ocasionalmente comida en emergencias. Deben hervirse para quitarle oxalatos. Las cenizas de las plantas incineradas se usaron como sustituto de la sal (Rapoport et al. 2009).

Uso forrajero (Verde Chaco 2002).

Raíces tiernas, hojas y tallos jóvenes, cocidos o hechos paté con queso crema (Rapoport et al. 2009).

Frutos maduros, frescos (Hurrell et al. 2010). En la zona se fabrica un licor.

Frutos tiernos se comen crudos; los maduros hervidos, asados u horneados, rellenos a modo de zapallitos. En el norte del país se prepara arrope o se conservan en almíbar (Hurrell et al. 2010).

Rizoma

Rizomas ricos en almidón, se comen crudo rayado $o$ hervido. cocidos o para espesar sopas y salsas. Las hojas tiernas son comestibles (Rapoport et al. 2009). 


\begin{tabular}{|c|c|c|c|c|}
\hline $\begin{array}{l}\text { Tomate de } \\
\text { árbol }\end{array}$ & $\begin{array}{l}\text { Solanum betaceum } \\
\text { Cav., Solanaceae }\end{array}$ & $\begin{array}{l}\text { Cultivado } \\
\text { (Amaya- } \\
\text { Robles y Julca- } \\
\text { Hashimoto } \\
\text { 2006) }\end{array}$ & $\begin{array}{l}\text { Frutos } \\
\text { crudos. }\end{array}$ & $\begin{array}{l}\text { Frutos frescos en jugos y bebidas, } \\
\text { helados, jaleas mermeladas y en platos } \\
\text { con carne (Amaya-Robles y Julca- } \\
\text { Hashimoto 2006) }\end{array}$ \\
\hline Tuna & $\begin{array}{l}\text { Opuntia ficus- } \\
\text { indica (L.) Mill., } \\
\text { Cactaceae }\end{array}$ & $\begin{array}{l}\text { Espontánea } \\
\text { (Hurrell et al. } \\
2010) \text {. }\end{array}$ & $\begin{array}{l}\text { Frutos } \\
\text { crudos. }\end{array}$ & $\begin{array}{l}\text { Frutos comestibles, frescos o } \\
\text { desecados, en mermeladas, arrope, } \\
\text { helados, tartas, jugos, licores y } \\
\text { aguardientes. Los cladiolos se comen } \\
\text { asados o cocidos, en ensaladas y } \\
\text { sopas, encurtidos o confitados } \\
\text { (Hurrell et al. 2010). }\end{array}$ \\
\hline $\begin{array}{l}\text { Vinagrillo } \\
\text { (oxalis) }\end{array}$ & $\begin{array}{l}\text { Oxalis corniculata } \\
\text { L., Oxalidaceae }\end{array}$ & $\begin{array}{l}\text { Espontánea } \\
\text { (Rapoport et } \\
\text { al. 2009). }\end{array}$ & $\begin{array}{l}\text { Hojas, que } \\
\text { saben a } \\
\text { vinagre, } \\
\text { crudas en } \\
\text { ensaladas. }\end{array}$ & $\begin{array}{l}\text { Hojas frescas o secas pueden comerse } \\
\text { como espinacas, pero no en exceso } \\
\text { debido a los oxalatos. Machacado en } \\
\text { mortero puede reemplazar al limón o } \\
\text { vinagre (Rapoport et al. 2009). }\end{array}$ \\
\hline $\begin{array}{l}\text { Yuyo } \\
\text { colorado }\end{array}$ & $\begin{array}{l}\text { Amaranthus bybridus } \\
\text { subsp. quitensis } \\
\text { (Kunth) Costea } \\
\text { \& Carretero, } \\
\text { Amaranthaceae }\end{array}$ & $\begin{array}{l}\text { Espontánea } \\
\text { (Rapoport et } \\
\text { al. 2009). }\end{array}$ & $\begin{array}{l}\text { Planta } \\
\text { entera, } \\
\text { cocida } \\
\text { como } \\
\text { espinaca. }\end{array}$ & $\begin{array}{l}\text { Hojas y partes tiernas, crudas o } \\
\text { cocidas como espinacas, se usan en } \\
\text { guisos, sopas, tartas, etc. (Rapoport et } \\
\text { al. 2009). }\end{array}$ \\
\hline Zarzaparrilla & $\begin{array}{l}\text { Mueblenbeckia } \\
\text { sagittifolia } \\
\text { (Ort) Meissn, }\end{array}$ & $\begin{array}{l}\text { Espontánea } \\
\text { (Rapoport et } \\
\text { al. 2009). }\end{array}$ & $\begin{array}{l}\text { Frutos } \\
\text { crudos. }\end{array}$ & $\begin{array}{l}\text { Frutos se comen crudos, en } \\
\text { mermeladas o fermentados de chicha } \\
\text { (Rapoport et al. 2009). }\end{array}$ \\
\hline
\end{tabular}

Tabla 2 - Plantas utilizadas con fines medicinales en el Parque Costero del Sur. Se indica nombre vulgar, nombre científico y familia, carácter espontáneo o cultivado, parte utilizada y usos en el Parque Costero del Sur y usos registrados en la bibliografía.

\begin{tabular}{|c|c|c|c|c|}
\hline $\begin{array}{l}\text { Nombre } \\
\text { vulgar }\end{array}$ & $\begin{array}{c}\text { Nombre } \\
\text { científico y } \\
\text { familia }\end{array}$ & $\begin{array}{l}\text { Espontánea/ } \\
\text { cultivada }\end{array}$ & $\begin{array}{c}\text { Parte utilizada } \\
\text { y usos en el PCS }\end{array}$ & $\begin{array}{c}\text { Usos registrados en la } \\
\text { bibliografía }\end{array}$ \\
\hline Abrojo & $\begin{array}{l}\text { Xanthium } \\
\text { spinosum L., } \\
\text { Asteraceae }\end{array}$ & $\begin{array}{l}\text { Espontánea } \\
\text { (Lahitte } \\
\text { y Hurrell } \\
\text { 1998). }\end{array}$ & $\begin{array}{l}\text { Hojas para curar } \\
\text { heridas de la } \\
\text { piel, mediante } \\
\text { la aplicación de } \\
\text { compresas. }\end{array}$ & $\begin{array}{l}\text { Raíz picada en el mate } \\
\text { es diurética, refrescante, } \\
\text { depurativa, digestiva, hepática, } \\
\text { carminativa, antitusiva, } \\
\text { emoliente, antimalárica y } \\
\text { antirreumática. Infusión para } \\
\text { enfermedades del pulmón y } \\
\text { riñón. La decocción en lavajes } \\
\text { cura llagas venéreas y es } \\
\text { antigangrenosa y vulneraria. } \\
\text { Hojas en aplicación externa } \\
\text { calman dolores de espalda y } \\
\text { reuma (Lahitte y Hurrell 1998) }\end{array}$ \\
\hline
\end{tabular}




\begin{tabular}{|c|c|c|c|c|}
\hline Aloe vera & $\begin{array}{l}\text { Aloe vera L., } \\
\text { Xanthorrhoeaceae }\end{array}$ & $\begin{array}{l}\text { Cultivada } \\
\text { (Vega et al. } \\
\text { 2005). }\end{array}$ & $\begin{array}{l}\text { Parte interna } \\
\text { de las hojas se } \\
\text { aplica sobre } \\
\text { la piel, en } \\
\text { quemaduras y } \\
\text { para mejorar el } \\
\text { pelo. También } \\
\text { es consumido } \\
\text { por personas } \\
\text { con cáncer para } \\
\text { calmar dolores. }\end{array}$ & $\begin{array}{l}\text { El exudado de las hojas es } \\
\text { catártico. El mucilago, utilizado } \\
\text { por la industria cosmética } \\
\text { y farmacéutica, aporta } \\
\text { suavidad y tersura a la piel. Se } \\
\text { emplea contra enfermedades } \\
\text { de la piel (dermatitis, } \\
\text { psoriasis) y quemaduras. } \\
\text { De acción antidisentérica, } \\
\text { antihemorroidal, cicatrizante, } \\
\text { laxante y colerética, combate } \\
\text { afecciones en ojos y desórdenes } \\
\text { intestinales. Es desinfectante, } \\
\text { antiviral, antibacterial, } \\
\text { laxante, antiinflamatorio e } \\
\text { inmunoestimulatorio (Vega et } \\
\text { al. 2005). }\end{array}$ \\
\hline Artemisia & $\begin{array}{l}\text { Artemisia } \\
\text { vulgaris L., } \\
\text { Asteraceae }\end{array}$ & $\begin{array}{l}\text { Espontánea } \\
\text { y a veces } \\
\text { cultivada } \\
\text { (Biblioteca } \\
\text { Digital de } \\
\text { la Medicina } \\
\text { Tradicional } \\
\text { Mexicana } \\
\text { 2009). }\end{array}$ & $\begin{array}{l}\text { Hojas y flores } \\
\text { en infusión, } \\
\text { para combatir } \\
\text { parásitos } \\
\text { y malestar } \\
\text { estomacal. }\end{array}$ & $\begin{array}{l}\text { En infusión las ramas tienen } \\
\text { acción antiparasitaria y las hojas } \\
\text { se consumen contra dolores } \\
\text { nerviosos (Biblioteca Digital } \\
\text { de la Medicina Tradicional } \\
\text { Mexicana 2009). }\end{array}$ \\
\hline Anacahuita & $\begin{array}{l}\text { Blepharocalyx } \\
\text { salicifolius } \\
\text { (Kunth) O. Berg, } \\
\text { Mirtaceae }\end{array}$ & $\begin{array}{l}\text { Espontánea } \\
\text { (Lahitte } \\
\text { y Hurrell } \\
\text { 1998). }\end{array}$ & $\begin{array}{l}\text { Hojas en forma } \\
\text { de vapor o } \\
\text { infusión, para la } \\
\text { tos y el resfrío. }\end{array}$ & $\begin{array}{l}\text { Cocimiento de hojas y corteza, } \\
\text { bebido con azúcar o miel, } \\
\text { es antitusivo, expectorante, } \\
\text { pectoral, astringente, } \\
\text { antidiarreico. El polvo de las } \\
\text { hojas en aplicación externa es } \\
\text { vulnerario (Lahitte y Hurrell } \\
\text { 1998). }\end{array}$ \\
\hline Burrito & $\begin{array}{l}\text { Aloysia } \\
\text { polystachya } \\
\text { (Griseb.) } \\
\text { Moldenke, } \\
\text { Verbenaceae }\end{array}$ & $\begin{array}{l}\text { Espontánea } \\
\text { (Hurrell et al. } \\
\text { 2008) }\end{array}$ & $\begin{array}{l}\text { Hojas y tallitos } \\
\text { en infusión, } \\
\text { como digestivo. }\end{array}$ & $\begin{array}{l}\text { Se emplea como remedio } \\
\text { digestivo (Hurrell et al. 2008). }\end{array}$ \\
\hline Carqueja & $\begin{array}{l}\text { Baccharis trimera } \\
\text { (Less.) DC., } \\
\text { Asteraceae }\end{array}$ & $\begin{array}{l}\text { Espontánea } \\
\text { (Lahitte } \\
\text { y Hurrell } \\
\text { 1998). }\end{array}$ & $\begin{array}{l}\text { Hojas y tallitos } \\
\text { en infusión o } \\
\text { masticados, para } \\
\text { el estómago } \\
\text { y problemas } \\
\text { hepáticos. }\end{array}$ & $\begin{array}{l}\text { Infusión de tallos y brotes es } \\
\text { tónica, digestiva, hepática, } \\
\text { diurética, antidiarreica, } \\
\text { febrífuga y cardiotónica. } \\
\text { Cocimiento en lavajes se utiliza } \\
\text { contra reuma, llagas, heridas } \\
\text { y quemaduras, e incluso en } \\
\text { algunas zonas se considera } \\
\text { afrodisíaco o anticonceptivo } \\
\text { (Lahitte y Hurrell 1998). }\end{array}$ \\
\hline
\end{tabular}




\begin{tabular}{|c|c|c|c|c|}
\hline Edrón & $\begin{array}{l}\text { Aloysia } \\
\text { citriodora } \text { Palau, } \\
\text { Verbenaceae }\end{array}$ & $\begin{array}{l}\text { Espontánea } \\
\text { (Lahitte } \\
\text { y Hurrell } \\
1998 \text { ). }\end{array}$ & $\begin{array}{l}\text { Hojas y tallitos } \\
\text { en infusión, para } \\
\text { dolor estomacal. } \\
\text { También en el } \\
\text { mate para evitar } \\
\text { que haga mal al } \\
\text { estómago. }\end{array}$ & $\begin{array}{l}\text { Infusión de tallos y hojas es } \\
\text { digestiva, carminativa y tónica; } \\
\text { en paños se aplica en la cabeza } \\
\text { contra palpitaciones, histerismo } \\
\text { y enfermedades nerviosas } \\
\text { (Lahitte y Hurrell 1998). }\end{array}$ \\
\hline Ceibo & $\begin{array}{l}\text { Erythrina crista } \\
\text { galli L., Fabaceae }\end{array}$ & $\begin{array}{l}\text { Espontánea } \\
\text { (Hurrell } \\
\text { 2004). }\end{array}$ & $\begin{array}{l}\text { Corteza hervida } \\
\text { en asientos para } \\
\text { hemorroides. }\end{array}$ & $\begin{array}{l}\text { Cocimiento de la corteza, } \\
\text { en tomas es antiasmática y } \\
\text { astringente y en baños de } \\
\text { asientos cura hemorroides, } \\
\text { fresca y machacada, en } \\
\text { cataplasmas sobre las heridas, } \\
\text { lastimaduras y contra empeine. } \\
\text { La decocción de las hojas en } \\
\text { tomas es hipnótica y sedativa. } \\
\text { El jarabe de las flores en tomas } \\
\text { es expectorante, pectoral y } \\
\text { antitusivo (Lahitte y Hurrell } \\
\text { 1998). }\end{array}$ \\
\hline Cerraja & $\begin{array}{l}\text { Sonchus } \\
\text { oleraceus L., } \\
\text { Asteraceae }\end{array}$ & $\begin{array}{l}\text { Espontánea } \\
\text { (Rapoport et } \\
\text { al. 2009). }\end{array}$ & $\begin{array}{l}\text { Hojas en } \\
\text { infusión. }\end{array}$ & $\begin{array}{l}\text { Cocción hojas se bebe } \\
\text { como antitusivo, hepático y } \\
\text { antinefrítico, y en lavajes se } \\
\text { usa para curar úlceras varicosas } \\
\text { (Lahitte y Hurrell 1998). }\end{array}$ \\
\hline $\begin{array}{l}\text { Cola de } \\
\text { caballo }\end{array}$ & $\begin{array}{l}\text { Equisetum } \\
\text { giganteum L., } \\
\text { Equisetaceae }\end{array}$ & $\begin{array}{l}\text { Espontánea } \\
\text { (Lahitte } \\
\text { y Hurrell } \\
\text { 1998). }\end{array}$ & $\begin{array}{l}\text { La parte aérea } \\
\text { en infusión, es } \\
\text { diurética. }\end{array}$ & $\begin{array}{l}\text { La planta entera en decocción } \\
\text { se bebe como diurético, } \\
\text { antinefrítico, astringente, } \\
\text { hepático, digestivo, } \\
\text { antidiarreico, antiblenorrágico, } \\
\text { emenagogo y pectoral. En } \\
\text { lavajes es tónico capilar y en } \\
\text { fomentos, vulnerario. El polvo } \\
\text { de la planta se ingiere como } \\
\text { antidisentérico (Lahitte y } \\
\text { Hurrell 1998). }\end{array}$ \\
\hline Eucalipto & $\begin{array}{l}\text { Eucaliptus } \\
\text { globulus Labill, } \\
\text { y otras sp. del } \\
\text { género, Mirtaceae }\end{array}$ & $\begin{array}{l}\text { Cultivada } \\
\text { (Botanical } \\
\text { online 2015). }\end{array}$ & $\begin{array}{l}\text { Hojas en } \\
\text { infusión, en } \\
\text { forma de vapor } \\
\text { o té, como } \\
\text { descongestivo. }\end{array}$ & $\begin{array}{l}\text { Muy utilizado contra } \\
\text { enfermedades respiratorias, es } \\
\text { antimicrobriano, antifúngico, } \\
\text { antiséptico e hipoglucemiente } \\
\text { (Botanical online 2015). }\end{array}$ \\
\hline Floripón & $\begin{array}{l}\text { Brugmansia } \\
\text { suaveolens } \\
\text { (Humb. \& Bonpl. } \\
\text { ex Willd.) Sweet., } \\
\text { Solanaceae }\end{array}$ & $\begin{array}{l}\text { Cultivada } \\
\text { (Flores- } \\
\text { Hernández } \\
\text { 2011). }\end{array}$ & $\begin{array}{l}\text { La flor se utiliza } \\
\text { en forma de } \\
\text { brebaje con miel, } \\
\text { para problemas } \\
\text { respiratorios. }\end{array}$ & $\begin{array}{l}\text { Tradicionalmente para aliviar } \\
\text { síntomas del resfrío, dolores de } \\
\text { cabeza, paperas, asma y dolores } \\
\text { reumatoides (Flores-Hernández } \\
\text { 2011). }\end{array}$ \\
\hline
\end{tabular}




\begin{tabular}{|c|c|c|c|c|}
\hline Laurel & $\begin{array}{l}\text { Laurus nobilis L., } \\
\text { Lauraceae }\end{array}$ & $\begin{array}{l}\text { Espontánea } \\
\text { y a veces } \\
\text { cultivada } \\
\text { (Hurrell et al. } \\
\text { 2008). }\end{array}$ & $\begin{array}{l}\text { Las hojas en } \\
\text { infusión para el } \\
\text { dolor de panza. }\end{array}$ & $\begin{array}{l}\text { Se emplea en medicina popular } \\
\text { como estomacal, carminativo } \\
\text { y emenagogo (Hurrell et al. } \\
\text { 2008). }\end{array}$ \\
\hline Llantén & $\begin{array}{l}\text { Plantago major } \\
\text { L., Plantaginaceae }\end{array}$ & $\begin{array}{l}\text { Espontánea } \\
\text { (Rapoport et } \\
\text { al. 2009). }\end{array}$ & $\begin{array}{l}\text { Hoja se aplican } \\
\text { directamente } \\
\text { machacadas } \\
\text { sobre } \\
\text { lastimaduras de } \\
\text { la piel. }\end{array}$ & $\begin{array}{l}\text { Las hojas frescas sobre heridas } \\
\text { o quemaduras desinfectan, } \\
\text { favorece la cicatrización y } \\
\text { calma el dolor. De gran uso } \\
\text { en la industria de la cosmética } \\
\text { (Blanco et al. 2008). Las } \\
\text { semillas enteras tienen efecto } \\
\text { laxante (Rapoport et al. 2009). }\end{array}$ \\
\hline Lucera & $\begin{array}{l}\text { Pluchea sagittalis } \\
\text { (Lam.) Cabrera, } \\
\text { Asteraceae }\end{array}$ & $\begin{array}{l}\text { Espontánea } \\
\text { (Hurrell et al. } \\
\text { 2008). }\end{array}$ & $\begin{array}{l}\text { Las hojas, flores } \\
\text { y tallitos se usan } \\
\text { en infusión, } \\
\text { así como en el } \\
\text { mate o tereré, } \\
\text { como digestivo y } \\
\text { contra la acidez. }\end{array}$ & $\begin{array}{l}\text { La infusión de las hojas se } \\
\text { emplea para combatir dolores } \\
\text { de estómago e hígado, náuseas, } \\
\text { indigestión y empacho, } \\
\text { así como antirreumático, } \\
\text { antihistérico y carminativo; a } \\
\text { veces mezclada con cedrón y } \\
\text { paico (Hurrell et al. 2008). }\end{array}$ \\
\hline $\begin{array}{l}\text { Malva } \\
\text { Rubia }\end{array}$ & $\begin{array}{l}\text { Marrubium } \\
\text { vulgare L., } \\
\text { Lamiaceae }\end{array}$ & $\begin{array}{l}\text { Espontánea } \\
\text { (Hurrell et al. } \\
\text { 2008). }\end{array}$ & $\begin{array}{l}\text { Las hojas } \\
\text { hervidas para } \\
\text { hemorroides, } \\
\text { en forma de } \\
\text { asientos y té y } \\
\text { para el hígado en } \\
\text { tomas. }\end{array}$ & $\begin{array}{l}\text { Se emplea como expectorante, } \\
\text { antitusivo, febrífugo, diurético, } \\
\text { emenagogo, depurativo, } \\
\text { digestivo y adelgazante. En } \\
\text { dosis elevadas puede ser } \\
\text { purgante. El polvo de las } \\
\text { hojas se ha empleado como } \\
\text { vermífugo. La planta fresca } \\
\text { se ha utilizado para elaborar } \\
\text { caramelos para la tos y el dolor } \\
\text { de garganta (Hurrell et al. } \\
\text { 2008). }\end{array}$ \\
\hline Manzanilla & $\begin{array}{l}\text { Matricaria } \\
\text { recutita } \mathrm{L} ., \\
\text { Asteraceae }\end{array}$ & $\begin{array}{l}\text { Espontánea } \\
\text { (Lahitte } \\
\text { y Hurrell } \\
1998 \text { ). }\end{array}$ & $\begin{array}{l}\text { Parte aérea en } \\
\text { infusión para el } \\
\text { dolor de panza. }\end{array}$ & $\begin{array}{l}\text { Las flores en infusión, } \\
\text { maceradas o decocción, en } \\
\text { tomas, como adelgazante, } \\
\text { refrescante, digestivo, hepático, } \\
\text { sedativo, febrífugo, emenagogo, } \\
\text { antinefrítico, emoliente, } \\
\text { pectoral y antitusivo. En baños, } \\
\text { como cicatrizante de heridas, } \\
\text { llagas y quemaduras, y en } \\
\text { casos de reumatismo, gota, } \\
\text { lumbago y mialgias en general; } \\
\text { antioftálmico, aplicada en } \\
\text { compresas sobre el ojo (Lahitte } \\
\text { y Hurrell 1998). }\end{array}$ \\
\hline
\end{tabular}




\begin{tabular}{|c|c|c|c|c|}
\hline Mburucuyá & $\begin{array}{l}\text { Passiflora } \\
\text { coerulea L., } \\
\text { Passifloraceae }\end{array}$ & $\begin{array}{l}\text { Espontánea } \\
\text { (Lahitte } \\
\text { y Hurrell, } \\
1998 \text { ) }\end{array}$ & $\begin{array}{l}\text { Flores y hojas } \\
\text { en alcohol para } \\
\text { el dolor de } \\
\text { estómago. }\end{array}$ & $\begin{array}{l}\text { Infusión de las hojas es sedativa, } \\
\text { hipotensora, cardiotónica, } \\
\text { emenagoga, vermífugo y } \\
\text { para combatir el alcoholismo. } \\
\text { Los frutos se ingieren como } \\
\text { diuréticos, antiescorbúticos y } \\
\text { antiictéricos. Infusión o jarabe } \\
\text { de raíz contra la pulmonía } \\
\text { (Lahitte y Hurrell 1998). }\end{array}$ \\
\hline Ortiga & $\begin{array}{l}\text { Urtica urens L., } \\
\text { Urticaceae }\end{array}$ & $\begin{array}{l}\text { Espontánea } \\
\text { (Rapoport et } \\
\text { al. 2009). }\end{array}$ & $\begin{array}{l}\text { La planta entera } \\
\text { en infusión, } \\
\text { para malestar } \\
\text { estomacal y } \\
\text { presión arterial. } \\
\text { Se deja reposar } \\
\text { en agua } 24 \text { horas } \\
\text { y se toma el } \\
\text { líquido durante } \\
\text { tres días, tomar } \\
\text { nuevamente } \\
\text { luego de otros } \\
\text { tres días. }\end{array}$ & $\begin{array}{l}\text { Se usa para combatir problemas } \\
\text { de circulación, riñones, tos y } \\
\text { caída de cabello (Arias-Toledo } \\
\text { 2009). }\end{array}$ \\
\hline $\begin{array}{l}\text { Palán- } \\
\text { palán }\end{array}$ & $\begin{array}{l}\text { Nicotiana } \\
\text { glauca Graham, } \\
\text { Solanaceae }\end{array}$ & $\begin{array}{l}\text { Espontánea } \\
\text { (Lahitte } \\
\text { y Hurrell } \\
\text { 1998). }\end{array}$ & $\begin{array}{l}\text { Hojas se aplican } \\
\text { sobre la piel para } \\
\text { curar heridas. }\end{array}$ & $\begin{array}{l}\text { Hojas, en cataplasmas contra } \\
\text { reuma, llagas, lastimaduras y } \\
\text { quemaduras. Hojas cocidas en } \\
\text { fomentos contra hemorroides y } \\
\text { hojas frescas o flameadas para } \\
\text { las paperas (Lahitte y Hurrell } \\
\text { 1998). }\end{array}$ \\
\hline $\begin{array}{l}\text { Pezuña de } \\
\text { vaca }\end{array}$ & $\begin{array}{l}\text { Bauhinia } \\
\text { forticata Link } \\
\text { subsp. pruinosa } \\
\text { (Vogel) Fortunato } \\
\text { et Wunderlin, } \\
\text { Fabaceae }\end{array}$ & $\begin{array}{l}\text { Espontánea } \\
\text { (Lahitte } \\
\text { y Hurrell } \\
\text { 1998). }\end{array}$ & $\begin{array}{l}\text { Hojas en té o en } \\
\text { el mate, para la } \\
\text { diabetes. }\end{array}$ & $\begin{array}{l}\text { Infusión de las hojas es } \\
\text { antidiabética, antinefrítica, } \\
\text { diurética y antitusiva; en } \\
\text { fomentos es vulneraria y } \\
\text { anticaspa. La infusión de las } \\
\text { flores es digestiva, astringente } \\
\text { y antihemorroidal (Lahitte y } \\
\text { Hurrell 1998). }\end{array}$ \\
\hline $\begin{array}{l}\text { Rompe } \\
\text { piedras }\end{array}$ & $\begin{array}{l}\text { Phyllanthus } \\
\text { niruri L. subsp. } \\
\text { lathyroides } \\
\text { (Kunth) Webster, } \\
\text { Phyllantaceae }\end{array}$ & $\begin{array}{l}\text { Espontánea } \\
\text { (Lahitte } \\
\text { y Hurrell } \\
\text { 1998). }\end{array}$ & $\begin{array}{l}\text { La planta entera } \\
\text { en el mate o } \\
\text { tereré, para } \\
\text { cálculos en los } \\
\text { riñones. }\end{array}$ & $\begin{array}{l}\text { Decocción de las hojas en tomas } \\
\text { es diurética, antidiabética, } \\
\text { astringente, antidisentería, } \\
\text { para disolver cálculos renales, } \\
\text { contra enfermedades del riñón, } \\
\text { la vejiga, hidropesía y gota } \\
\text { (Lahitte y Hurrell 1998). }\end{array}$ \\
\hline
\end{tabular}




\begin{tabular}{|c|c|c|c|c|}
\hline Ruda & $\begin{array}{l}\text { Ruta chalepensis } \\
\text { L., Rutaceae }\end{array}$ & $\begin{array}{l}\text { Espontánea } \\
\text { y a veces } \\
\text { cultivada } \\
\text { (Lahitte } \\
\text { y Hurrell } \\
1998) .\end{array}$ & $\begin{array}{l}\text { Las hojas en } \\
\text { infusión para la } \\
\text { panza. También } \\
\text { en alcohol, } \\
\text { con alcanfor, } \\
\text { bayaspirina y } \\
\text { aloe para el dolor } \\
\text { de las piernas. } \\
\text { El primero de } \\
\text { agosto de cada } \\
\text { año se toma con } \\
\text { caña con ruda. }\end{array}$ & $\begin{array}{l}\text { Infusión de las hojas en tomas } \\
\text { es cardiotónica, rubefaciente, } \\
\text { digestiva, carminativa, } \\
\text { febrífuga, emenagoga. En altas } \\
\text { dosis es abortiva. Se cree que } \\
\text { es efectiva para curar el mal de } \\
\text { ojo. En paños calma la otitis. } \\
\text { Vermífuga. En Corrientes se } \\
\text { prepara una caña de ruda y } \\
\text { se toma el 1 de agosto para } \\
\text { liberarse de las enfermedades } \\
\text { por todo el año siguiente } \\
\text { (Lahitte y Hurrell 1998). }\end{array}$ \\
\hline $\begin{array}{l}\text { Ruda } \\
\text { hembra }\end{array}$ & $\begin{array}{l}\text { Ruta graveolens } \\
\text { L., Rutaceae }\end{array}$ & $\begin{array}{l}\text { Espontánea } \\
\text { (Rapoport et } \\
\text { al. 2009). }\end{array}$ & $\begin{array}{l}\text { Infusión de } \\
\text { las hojas se } \\
\text { bebe como } \\
\text { antiparasitario. }\end{array}$ & $\begin{array}{l}\text { Se usa para evitar el escorbuto, } \\
\text { como emenagogo y para detener } \\
\text { la menstruación, eliminar } \\
\text { parásitos, calmar dolor de oídos } \\
\text { y para problemas gástricos. } \\
\text { Se debe utilizar siempre en } \\
\text { pequeñas cantidades por su } \\
\text { toxicidad (Flora bonaerense } \\
\text { 2012). }\end{array}$ \\
\hline $\begin{array}{l}\text { Santa } \\
\text { Lucia }\end{array}$ & $\begin{array}{l}\text { Commelina } \\
\text { erecta L., } \\
\text { Commelinaceae }\end{array}$ & $\begin{array}{l}\text { Espontánea } \\
\text { (Lahitte } \\
\text { y Hurrell } \\
1998 \text { ). }\end{array}$ & $\begin{array}{l}\text { Líquido de la } \\
\text { flor, como colirio } \\
\text { para ojos. }\end{array}$ & $\begin{array}{l}\text { El líquido y el mucílago } \\
\text { acumulado en las brácteas } \\
\text { florales se usan como colirio, } \\
\text { en caso de conjuntivitis. La } \\
\text { decocción de las flores tiene } \\
\text { el mismo uso. El zumo de la } \\
\text { planta, en lavajes, calma el } \\
\text { prurito y la urticaria (Lahitte y } \\
\text { Hurrell 1998). }\end{array}$ \\
\hline Sarandí & $\begin{array}{l}\text { Phyllanthus } \\
\text { sellowianus } \\
\text { Müll. Arg., } \\
\text { Phyllantaceae }\end{array}$ & $\begin{array}{l}\text { Espontánea } \\
\text { (Lahitte } \\
\text { y Hurrell } \\
1998 \text { ). }\end{array}$ & Sin precisar. & $\begin{array}{l}\text { Infusión de la corteza, ramas } \\
\text { y hojas contra la diabetes, } \\
\text { emenagoga y antidiarreica. La } \\
\text { decocción de las hojas, en tomas } \\
\text { es antiasmática, purgante y } \\
\text { diurética. En aplicación externa } \\
\text { es vulneraria. (Lahitte y Hurrell } \\
\text { 1998). }\end{array}$ \\
\hline Sauce & $\begin{array}{l}\text { Salix humboldtina } \\
\text { Wild., Salicaceae }\end{array}$ & $\begin{array}{l}\text { Espontánea } \\
\text { y cultivada } \\
\text { (Lahitte } \\
\text { y Hurrell } \\
1998) .\end{array}$ & $\begin{array}{l}\text { Corteza en } \\
\text { infusión, para el } \\
\text { dolor de cabeza. }\end{array}$ & $\begin{array}{l}\text { Decocción de la corteza se bebe } \\
\text { como sucedáneo de la quinina; } \\
\text { es febrífuga, analgésica, } \\
\text { sedativa, tónica, antirreumática, } \\
\text { astringente y digestiva. La } \\
\text { ceniza de la corteza, en } \\
\text { macerados, para afecciones } \\
\text { cutáneas. Las hojas hervidas con } \\
\text { shampoo, dan brillo al cabello } \\
\text { (Lahitte y Hurrell 1998). }\end{array}$ \\
\hline
\end{tabular}




\begin{tabular}{|c|c|c|c|c|}
\hline $\begin{array}{l}\text { Sombra de } \\
\text { toro }\end{array}$ & $\begin{array}{l}\text { Jodina } \\
\text { rhombifolia } \\
\text { Hook. et Arn, } \\
\text { Santalaceae }\end{array}$ & $\begin{array}{l}\text { Espontánea } \\
\text { (Lahitte } \\
\text { y Hurrell } \\
1998 \text { ). }\end{array}$ & Sin precisar. & $\begin{array}{l}\text { Infusión de las hojas en } \\
\text { tomas es digestiva, hepática, } \\
\text { antihidrópica, pectoral, } \\
\text { antiasmática y antialcohólica; } \\
\text { la decocción de la corteza en } \\
\text { tomas es antidisentérica. El } \\
\text { zumo del fruto en aplicación } \\
\text { externa cura llagas venéreas } \\
\text { (Lahitte y Hurrell 1998). }\end{array}$ \\
\hline Tala & $\begin{array}{l}\text { Celtis } \\
\text { ehrenbergiana } \\
\text { (Klotzsch) } \\
\text { Liebm., } \\
\text { Celtidaceae }\end{array}$ & $\begin{array}{l}\text { Espontánea } \\
\text { (Lahitte } \\
\text { y Hurrell } \\
\text { 1998, Torres- } \\
\text { Robles y } \\
\text { Arturi 2009). }\end{array}$ & $\begin{array}{l}\text { Semillas se } \\
\text { mastican contra } \\
\text { el estreñimiento. }\end{array}$ & $\begin{array}{l}\text { La infusión de las hojas con } \\
\text { miel para catarros, tos, dolores } \\
\text { de pecho, de cabeza, de hígado, } \\
\text { diarreas e indigestiones. Las } \\
\text { hojas frescas se refriegan sobre } \\
\text { la piel para curar el empeine. } \\
\text { Decocción de la corteza para } \\
\text { abrir el apetito. (Hurrell y } \\
\text { Lahitte 1998). }\end{array}$ \\
\hline $\begin{array}{l}\text { Yerba de } \\
\text { pollo }\end{array}$ & $\begin{array}{l}\text { Alternanthera } \\
\text { pungens Kunth, } \\
\text { Amarantaceae }\end{array}$ & $\begin{array}{l}\text { Espontánea } \\
\text { (Lahitte } \\
\text { y Hurrell } \\
1998 \text { ). }\end{array}$ & $\begin{array}{l}\text { La parte aérea en } \\
\text { infusión se toma } \\
\text { para el empacho. }\end{array}$ & $\begin{array}{l}\text { Decocción de la raíz, en tomas } \\
\text { es antidiarreica y digestiva. } \\
\text { La decocción de la planta se } \\
\text { bebe como hepática y junto } \\
\text { con raíces de yerba de la vida } \\
\text { se bebe como digestivo. La } \\
\text { planta en infusión en tomas, } \\
\text { es diurética, emoliente y } \\
\text { depurativa, empleada para } \\
\text { el tratamiento de la sífilis y } \\
\text { enfermedades cutáneas (Lahitte } \\
\text { y Hurrell 1998). }\end{array}$ \\
\hline
\end{tabular}

Figura 4 -Algunas plantas utilizadas con fines alimenticios en el Parque Costero del Sur. A-Arania sericifera (tasi); B-Oxalis corniculata (vinagrillo); C-Taraxacum officinale (diente de león); D-Sonchus asper (cerraja brava).
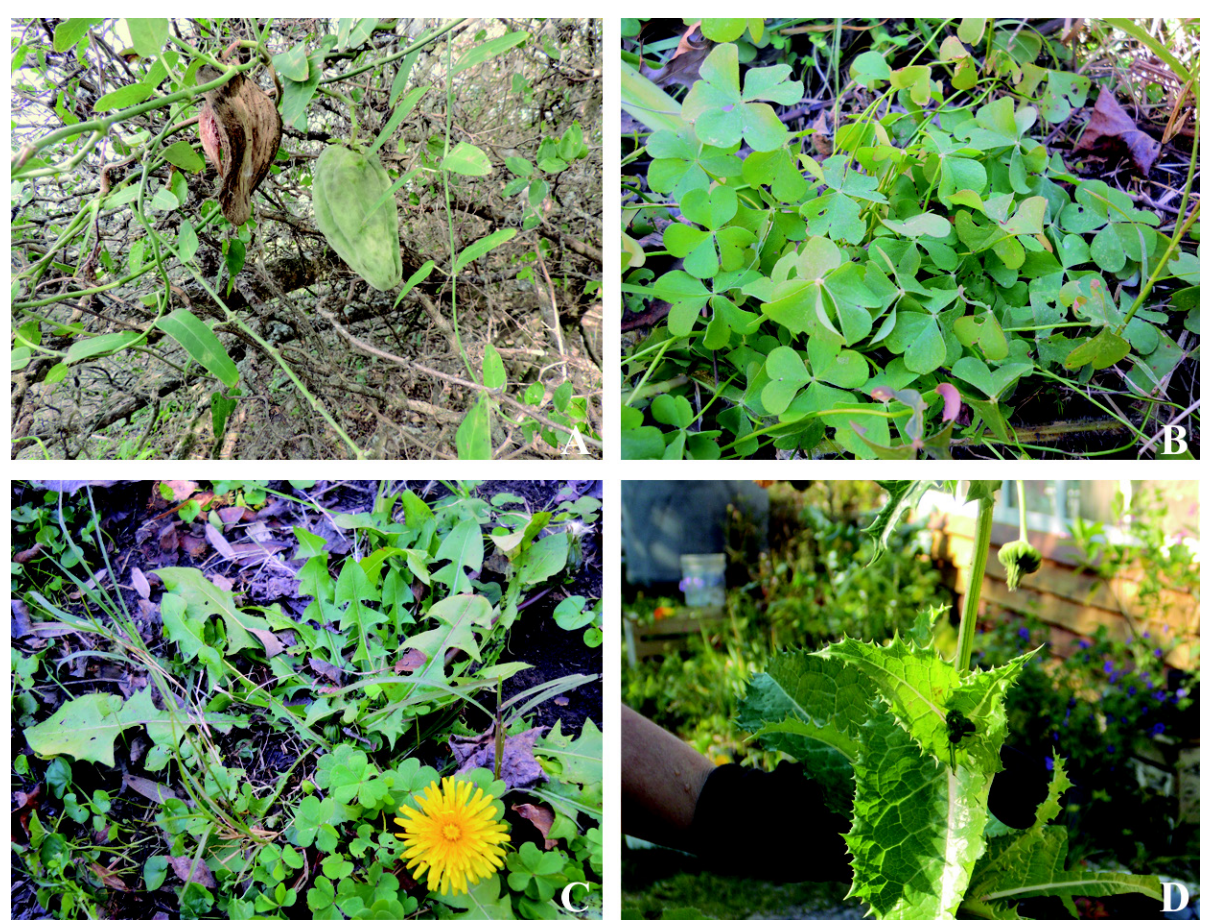
Figura 5 - Algunas plantas utilizadas con fines medicinales en el Parque Costero del Sur. A- Erythrina crista galli (ceibo); B-Nicotiana glauca (palán-palán); C-Jodina rhombifolia (sombra de toro); D- Baccharis trímera (carqueja).
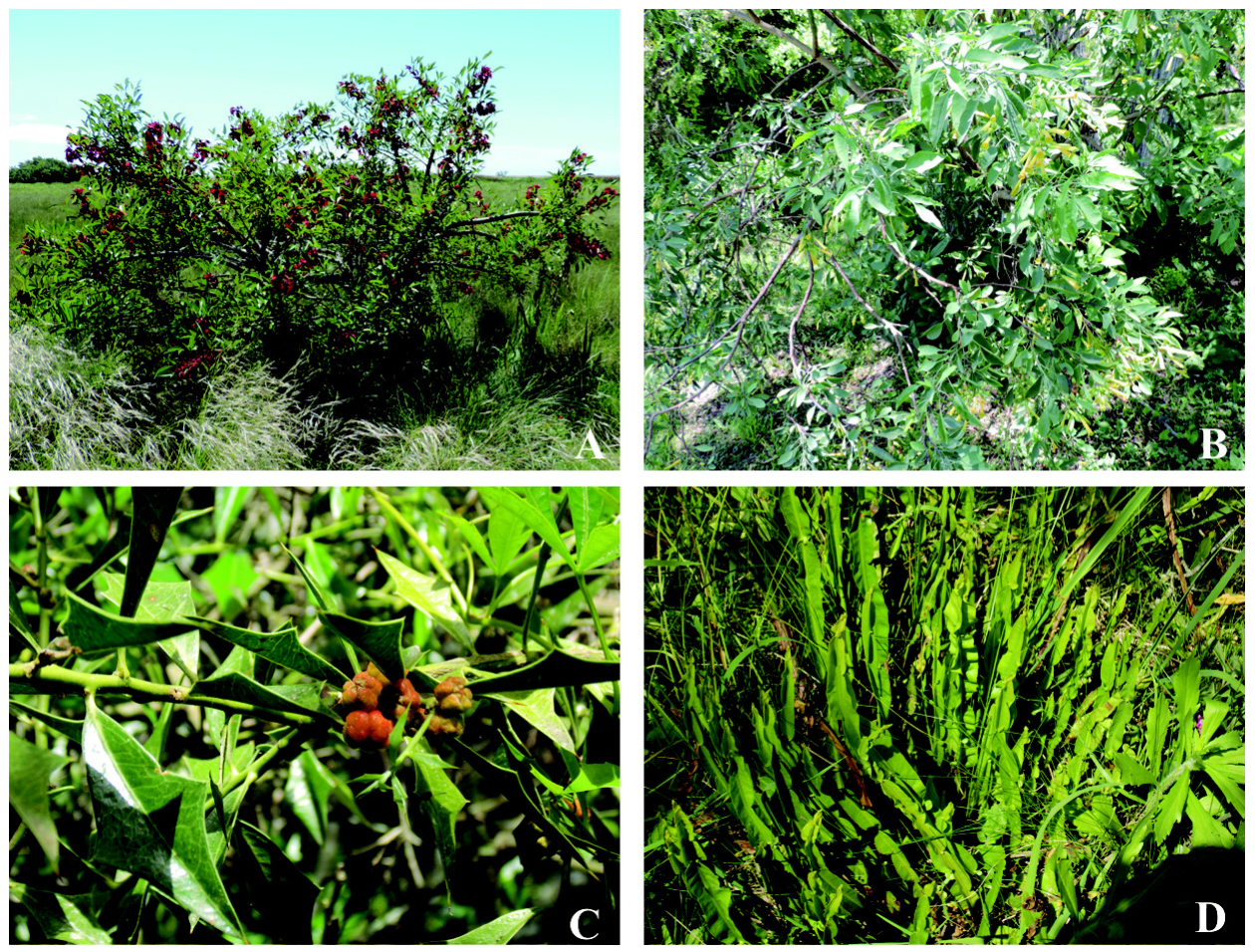

Figura 6 - Algunas plantas utilizadas con fines alimenticios y medicinales en el Parque Costero del Sur. A-Celtis ehrenbergiana (tala); B- Passiflora coerulea (mburucuyá); C- Laurus nobilis (laurel); D-Plantago major (llantén).
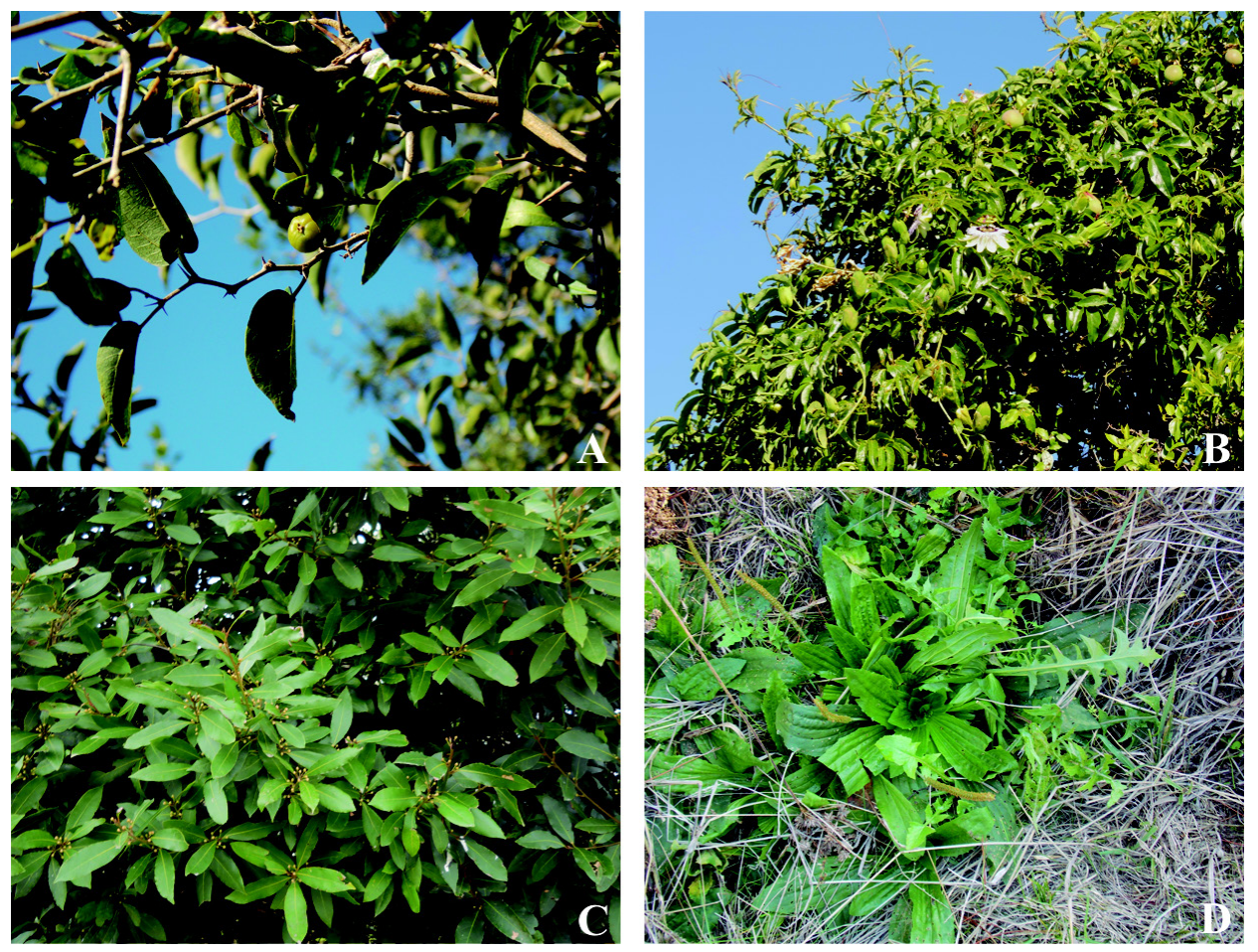

La comparación en el número de especies alimenticias y medicinales recolectadas no permitió comprobar el supuesto planteado en la introducción, referido a una recolección preferencial y mayor conocimiento acerca de los recursos terapéuticos (Figura 7). Al respecto cabe hacer varias reflexiones. En relación a las plantas medicinales, 
el número relevado fue menor al esperado teniendo en cuenta algunas zonas vecinas y fitogeográficamente similares como Isla Santiago y Palo Blanco (Hernández 2010, 2011) donde se registraron 40 y 60 especies respectivamente. Sin embargo, si en estas localidades el análisis considerase únicamente las plantas recolectadas, dejando de lado aquellas cultivadas por los pobladores, el número obtenido sería similar al presentado en este trabajo (20 y 30 respectivamente), donde se indagó exclusivamente sobre las espontáneas.

Figura 7 - Cantidad de plantas alimenticias y medicinales mencionadas por entrevista.

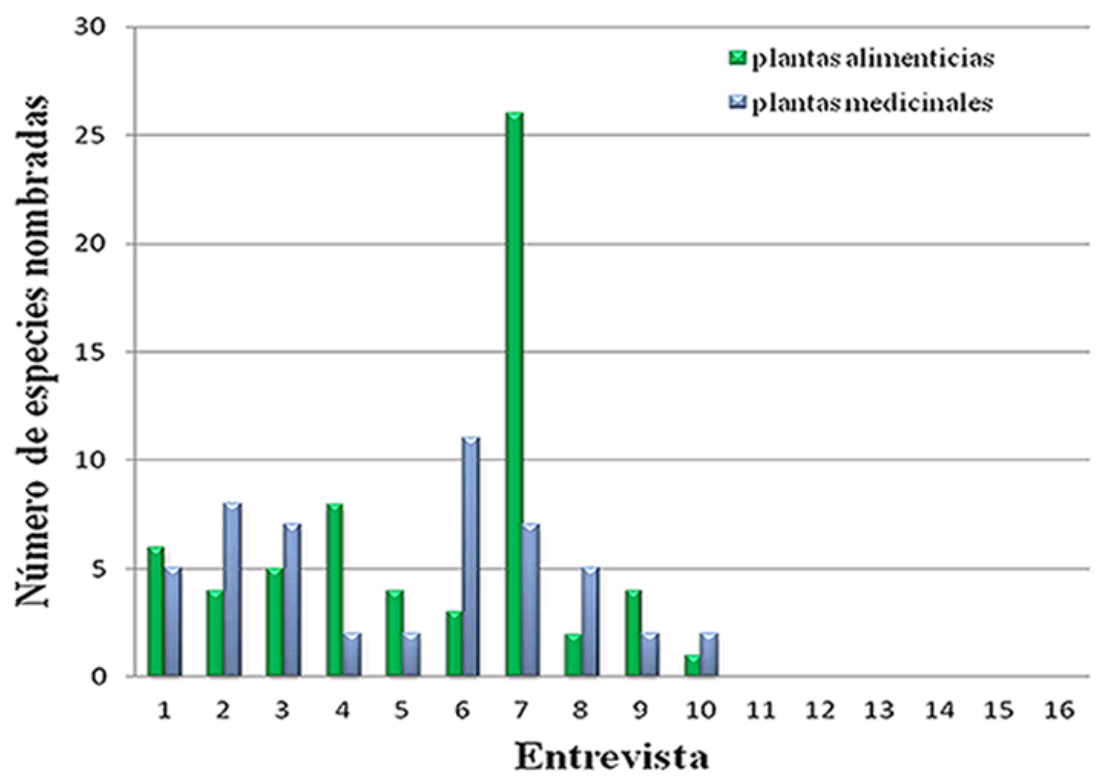

Por otra parte, cabe destacar que el elevado número de especies alimenticias nombradas se deben a una persona capacitada en producción de plantas y paisajismo, que organiza talleres y caminatas de plantas silvestres comestibles en la zona. Su aporte corresponde a las casillas de color gris de la Tabla 1.

Se registraron 26 y 19 familias botánicas en las especies mencionadas como alimenticias y medicinales respectivamente; en ambos casos la más representada es Asteraceae, una de las familias más utilizadas como alimento y medicina en la mayor parte de las culturas modernas. Otras familias destacadas son Myrtaceae y Solanaceae, también de gran relevancia económica. Las especies más citadas como alimenticias en orden decreciente fueron tala, mora, mburucuyá y diente de león, en tanto que las medicinales más citadas fueron en primer lugar carqueja y en un segundo lugar y con la misma cantidad de menciones, eucalipto, lucera, malva rubia y aloe. En este listado se observa que se reconocen como propias de la zona especies tanto nativas como exóticas e incluso escapadas de cultivo, como laurel y tuna, o bien aquellas resultantes de cultivos antiguos y que se mantienen por generaciones, tal el caso del aloe, guayabo y falso guayabo. La característica espontánea o cultivada, independientemente de la percepción local recientemente mencionada, se aclara en las tablas correspondientes. En cuanto a la parte del vegetal más utilizada, en ambos casos fue la hoja, pero en las medicinales el segundo lugar lo ocupa toda la parte aérea de la planta mientras que en las alimenticias lo ocupan los frutos.

La forma de uso más común en medicinales es la preparación de té, mate o refrescos y luego, la aplicación directa del vegetal o mediante compresas sobre la piel. La cantidad de efectos terapéuticos registrados fue de 15, siendo el más habitual el digestivo. Por otro lado, la forma de consumo más frecuente de las alimenticias es mediante el consumo directo crudo del vegetal, en segundo lugar hervido y en tercer lugar preparación de dulces. 
Al comparar los usos registrados (efectos terapéuticos, preparaciones) con la bibliografía (Tablas 1 y 2), se observa que en el caso de las alimenticias coinciden mayoritariamente. En cambio, en cuanto a las medicinales, si bien también hay coincidencias, se registraron menos usos que los citados en la bibliografía e incluso se registraron plantas como el sarandí, de propiedades hipoglucemiantes bien conocidas, que fue mencionada pero con desconocimiento de su utilidad. Estas situaciones remiten nuevamente a la influencia de actores sociales determinados con un saber especial, en muchos casos obtenido de la bibliografía circulante, en contraposición a un conocimiento consensuado que se pierde junto con el despoblamiento y la pérdida de la práctica de recolección.

De lo expuesto se desprende el dispar conocimiento de los pobladores acerca de las plantas silvestres alimenticias y medicinales. Si bien razones metodológicas como un bajo tamaño muestral podrían incidir en estos aspectos, a través de las entrevistas surgen como motivo principal las distintas historias de vida y vinculación con el entorno de los pobladores entrevistados. Cabe destacar que a nivel comunitario se han identificado pobladores con amplio conocimiento de los recursos vegetales que se ocupan de su protección y difusión es así que esta iniciativa local lleva a reflexionar sobre las características que asume la transmisión del conocimiento. Soldati et al. (2015) pusieron a prueba la hipótesis de que en situaciones de cambio socio-ambiental se favorece la innovación y la transmisión horizontal del conocimiento (entre personas de una misma generación). Estos autores realizaron sus estudios en tres poblados del norte de Mina Gerais (Brasil) y observaron que si bien la transmisión vertical (entre generaciones) seguía siendo la principal vía de adquisición de saberes para las nuevas generaciones, en la localidad con mayor inestabilidad se incrementaba el intercambio entre pares. Trabajos de esta naturaleza llevan a reflexionar sobre el papel de los innovadores en la zona de estudio. La incorporación de saberes novedosos a partir de estos actores, resulta un aporte para los emprendimientos locales, por ejemplo el turismo rural. En este caso, sería de esperar la apropiación de estos conocimientos por parte del resto de los habitantes y de este modo el incremento en la transmisión horizontal. Aún cuando parte de la información que estos innovadores difunden es ajena a la zona en estudio, su actividad resulta de suma importancia ya que ayuda a reafirmar el vínculo con la diversidad local y poner en práctica los conocimientos que los pobladores poseen, a veces sólo nominalmente, o a revalorizar una actividad menospreciada. En este sentido, contribuyen a la salvaguardia de esos saberes como patrimonio intangible.

\section{CONSIDERACIONES FINALES}

Los resultados obtenidos muestran un panorama a primera vista poco favorable para la constitución de los saberes locales como patrimonio intangible. Si bien como proyección futura se considera la ampliación del tamaño muestral para dar mayor respaldo a estas apreciaciones e indagar con mayor detalle las formas de transmisión de los conocimientos, el panorama descripto es coincidente con la historia del PCS ya que éste fue creado como área protegida sin participación de los pobladores, y durante mucho tiempo tuvo una existencia prácticamente virtual. No obstante, existen varios factores promisorios a tener en cuenta. En primer lugar hay una apropiación de la flora y reconocimiento de la misma como característica de la zona, independientemente de su origen nativo o exótico. Asimismo, si bien los saberes se hayan dispersos y el consenso entre los informantes es bajo, el número de especies localmente reconocidas como útiles es similar al de enclaves vecinos en el mismo tipo de ambiente. Finalmente, se destaca la presencia de actores sociales con un saber especial, innovadores en 
cuanto a su difusión al público, que actuarían como potenciadores del conocimiento botánico local.

Con los resultados obtenidos en este trabajo se propone fomentar la participación de los pobladores en actividades de capacitación sobre recursos vegetales locales, organizadas y realizadas por miembros de la comunidad. Se propone incentivar la continuidad de los talleres y caminatas que favorezcan el reconocimiento de plantas silvestres comestibles, así como la incorporación de las plantas medicinales en estas actividades. Otras acciones de importancia a nivel local son aquellas que dejan registro a través del tiempo. En este sentido se plantea la realización de una cartilla con las especies relevadas durante este trabajo y la información asociada con imágenes que faciliten su identificación. También cobra importancia la gestión de los recursos necesarios para la continuidad de estas actividades, que a futuro posibilitarían el autofinanciamiento a través de los emprendimientos turísticos mencionados y tendientes al desarrollo de la población del PCS.

\section{Agradecimentos}

A los pobladores de Punta del Indio y Punta Piedras que han colaborado con el desarrollo de este trabajo y han autorizado la difusión de los resultados. Este estudio se realizó con el apoyo financiero de FONCyT y UNLP.

\section{REFERENCIAS}

Abba AM, Merino ML y Vizcaíno SF. 2009. Mamíferos del Parque Costero del Sur: caracterización general y un ejemplo de trabajo. En: Athor J. (ed.), Parque Costero del Sur. Naturaleza, conservación y patrimonio cultural, Buenos Aires: Fundación de Historia natural Félix de Azara, p. 172-199.

Alvarado V, Rahim-Foroughbakhch MA, Jurado E y Rocha A. 2004. Caracterización morfológica y nutricional del fruto de anacahuita (Cordia boissieri A. DC.) en dos localidades del Noreste de México. Phyton, 73: 85-90.

Amaya-Robles JE y Julca-Hashimoto JL. 2006. Tomate de árbol (Cyphomandra betacea Send.) Trujillo: Gerencia Regional de Recursos Naturales y conservación del Medio Ambiente. Área de Biodiversidad y Conservación de los Recursos Fitogenéticos Andinos. Disponible en <http://www.regionlalibertad.gob.pe/web/opciones/ pdfs/Manual $\% 20 \mathrm{de} \% 20$ Tomate $\% 20 \mathrm{de} \% 20 \%$ C3\%A1rbol.pdf $>$ Último acceso 20-7-2015].

Arias-Toledo B. 2009. Diversidad de usos, prácticas de recolección y diferencias según género y edad en el uso de plantas medicinales en Córdoba, Argentina. Boletín Latinoamericano y del Caribe de Plantas Medicinales y Aromáticas, 8 (5): 389 -401.

Arturi M, Pérez-Meroni M, Paleo MC y Herrera R. 2009. Lineamientos para una zonificación del parque costero del sur basada en la relación del paisaje con la cultura. En: Athor J. (ed.), Parque Costero del Sur. Naturaleza, conservación y patrimonio cultural, Buenos Aires: Fundación de Historia natural Félix de Azara, p. 18-36.

Baxendale CA. 2009. Caracterización socio-espacial contextual del Parque Costero del Sur: importancia de las áreas naturales en el ordenamiento territorial. En: Athor J. (ed.), Parque Costero del Sur. Naturaleza, conservación y patrimonio cultural, Buenos Aires: Fundación de Historia natural Félix de Azara, p. 52-65. 
Biblioteca Digital de la Medicina Tradicional Mexicana. 2009. Atlas de las plantas de la medicina tradicional Mexicana. Ajenjo. Disponible en <http://www.medicinatradicionalmexicana.unam.mx/monografia. php?l=3\&t=Ajenjo\&id=7183 $>$ [Último acceso 16/7/2015].

Blanco B, Saborío A y Garro G. 2008. Descripción anatómica, propiedades medicinales y uso potencial de Plantago major (llantén mayor). Tecnología en Marcha, 21 (2): 17-24.

Botanical online. 2015. Propiedades medicinales del Eucalipto. Disponible en < $\underline{\text { http://www.botanical-online. }}$ com/medicinalseucalipto.htm> [Último acceso 24/6/2015].

Burkart R, Bárbaro NO, Sánchez RO y Gómez DA. 1999. Eco-regiones de la Argentina. Buenos Aires: Administración de Parques Nacionales, Secretaría de Recursos Naturales y Desarrollo Sustentable, Presidencia de la Nación, 43 p.

Cabrera AL. 1971. Fitogeografía de la República Argentina. Boletín de la Sociedad Argentina de Botánica, 14: $1-42$.

Cavallotto JL. 2002. Evolución holocena de la llanura costera del margen sur del Río de la Plata. Revista de la Asociación Geológica Argentina, 57 (4): 376-388.

Cavallotto JL. 2009. Caracterización e historia evolutiva del sustrato sobre el que se desarrollan los talares del nordeste bonaerense. En: Athor J (ed.) Parque Costero del Sur. Naturaleza, conservación y patrimonio cultural, Buenos Aires: Fundación de Historia natural Félix de Azara, p. 66-81.

CEPA 1989. Naturaleza y cultura pampeana en el mapa del mundo: Parque Costero del Sur. La Plata: Ediciones Ambiente, 200 p.

Delucchi G y Torres-Robles SS. 2009. Plantas exóticas en el Parque Costero del Sur: Una categorización. En: Athor J. (ed.) Parque Costero del Sur. Naturaleza, conservación y patrimonio cultural, Buenos Aires: Fundación de Historia natural Félix de Azara, p. 408-415.

Flora Bonaerense. 2012. Plantas y Hongos de la Provincia de Buenos Aires, Argentina. Disponible en $<\underline{\text { http: } / /}$ florabonaerense.blogspot.com.ar/2012/12/ruda-ruta-graveolens.html> [Último acceso 8/7/2015].

Flores-Hernández, MA. 2011. Compilación bibliográfica Brugmansia spp. Disponible en < $\underline{\text { http://core.ac.uk/ }}$ download/pdf/16305413.pdf> [Último acceso 24/6/2015].

Guglielmino MM. 2007. La difusión del patrimonio. Actualización y debate. Revista Electrónica de Patrimonio Histórico 1. Disponible en < http://www.revistadepatrimonio.es/revistas/numero1/difusion/estudios/articulo. php $>$ [Último acceso 31/7/2015].

Hernández MP, Civitella SM y Rosato VM. 2010. Uso medicinal popular de plantas y líquenes de la Isla Paulino, Provincia de Buenos Aires, Argentina. Boletín Latinoamericano y del Caribe de Plantas Medicinales y Aromáticas, 9 (4): 258-268.

Hernández MP y Arambarri. AM. 2011. Recursos fitoterapéuticos y comportamiento poblacional en la ribera 
rioplatense de Berisso, Buenos Aires, Argentina. Bonplandia, 20(2): 137-148.

Hurrell JA (ed.) 2004. Árboles rioplatenses. Biota Rioplatense III, Buenos Aires: Editorial L.O.L.A., 300 p. Hurrell JA, Ulibarri EA, Delucchi G y Pochettino ML. 2008. Plantas aromáticas condimenticias. Biota Rioplatense XIII, Buenos Aires: Editorial L.O.L.A., 268 p.

Hurrell JA, Ulibarri EA, Delucchi G y Pochettino ML. 2009. Hortalizas, verduras y legumbres. Biota Rioplatense XIV, Buenos Aires: Editorial L.O.L.A., 242 p.

Hurrell JA, Ulibarri EA, Delucchi G y Pochettino ML. 2010. Frutas frescas, secas y preservadas. Biota Rioplatense XV, Buenos Aires: Editorial L.O.L.A., 301 p.

IBODA. 2015. Flora del Conosur. Catálogo de Plantas Vasculares. Disponible en $<\underline{\text { http: } / / \text { www2.darwin.edu. }}$ ar/Proyectos/FloraArgentina/BuscarEspecies.asp> [Último acceso 25-6-2015]

Lahitte HB y Hurrell JA (eds.) 1997. Plantas de la Costa. Buenos Aires, Buenos Aires: Editorial L.O.L.A., $200 \mathrm{p}$.

Lahitte HB y Hurrell JA (eds.) 1998. Plantas Medicinales Rioplatenses, Buenos Aires: Editorial L.O.L.A., $240 \mathrm{p}$.

Paleo MC y Pérez Meroni M. 2010. Del bosque de tala al Parque Costero del Sur. En: Berón M, Luna L, Bonomo M, Montalvo C, Aranda C y Carrera-Aizpitarte M. (eds.), Mamül Mapu: Pasado y presente desde la arqueología pampeana 1, Ayacucho: Libros del Espinillo, p. 215-226.

Pochettino ML. 2005. Verduras en Europa, yuyos en América: prácticas y conocimientos sobre malezas comestibles. Actas Congreso Nacional Inmigración y IV Congreso de Historia de los pueblos de la provincia de Santa Fe. Esperanza, Santa Fe, en CD, 16 p.

Rapoport EH, Ladio A, Raffaele E, Ghermandi L y Sanz EH. 1988. Malezas Comestibles. Hay yuyos y yuyos... Ciencia Hoy, 9 (49): 30-43.

Rapoport EH, Marzocca A y Drausal BS. 2009. Malezas comestibles del Cono Sur y otras partes del planeta. San Carlos de Bariloche: Instituto Nacional de Tecnología Agropecuaria, 216 p.

Rossi E y Molinari G. 2012a. Espacios de encuentros y participación en busca de la construcción de un proceso de aprendizaje colectivo. Estudio de caso: El sistema educativo del distrito de Punta Indio, provincia de Buenos Aires. La Plata: XI INTI International Conference, 12 p. Disponible en $<$ http://territoriosposibles.fahce.unlp. edu.ar/> Último acceso 22-7-2015].

Rossi E y Molinari G. 2012b.El turismo como herramienta para la conservación del patrimonio natural: Reserva de Biosfera Parque Costero del Sur. La Plata: Actas VII Congreso de Medio Ambiente AUGM, 39 p. Disponible en <http://sedici.unlp.edu.ar/bitstream/handle/10915/26631/67-Elturismocomoherramientaparalaconserv acindelpatrimonionaturalreservadebiosferaparquecosterodelsur.pdf?sequence=1> [Último acceso 22-7-2015]. 
Soldati GT, Hanazaki N, Crivos My Albuquerque UP. 2015. Does Environmental Instability Favor the Production and Horizontal Transmission of Knowledge regarding Medicinal Plants? A Study in Southeast Brazil. PLoS ONE 10(5): e0126389. doi:10.1371/journal.pone.0126389

Stratta-Fernández R y De los Ríos-Carmenado I. 2010. Desarrollo rural en territorios rurales con problemas de despoblamiento: marco conceptual y análisis del caso de Punta del Indio, Argentina. Madrid: XIV International Congress on Project Engineering, p. 2034- 2045.

Torres-Robles SS y Arturi M. 2009. Variación de la composición y riqueza florística en los talares del Parque Costero del Sur y su relación con el resto de los talares bonaerenses. En: Athor J. (ed.), Parque Costero del Sur. Naturaleza, conservación y patrimonio cultural, Buenos Aires: Fundación de Historia natural Félix de Azara, p. 104-121.

UNESCO. 2003. Convención para la Salvaguardia del Patrimonio Cultural Inmaterial, Disponible en $<\underline{\text { http: } / /}$ www.unesco.org/culture/ich/index.php?lg=es\&pg=00006)> [Último acceso 31/7/2015].

Vega GA, Ampuero CN, Diaz NL y Lemus MR. 2005. El aloe vera (Aloe barbadensis Miller) como componente de alimentos funcionales. Revista chilena de nutrición [online], 32 (3): 208-214. Disponible en http://www. scielo.cl/scielo.php?script=sci_arttext\&pid=S0717-75182005000300005 [Último acceso 23/6/2015].

Verde Chaco. 2002. Sangre de Toro. Disponible en < http://arbolesdelchaco.blogspot.com.ar/2012/05/sangrede-toro.html> [Último acceso 10/7/2015]. 